Portland State University

PDXScholar

$1-1-2011$

\title{
Youth Voices of Bounty and Opportunity: High School Students' Experiences With Food and Community
}

Kara Marie Gilbert

Portland State University

Follow this and additional works at: https://pdxscholar.library.pdx.edu/open_access_etds Let us know how access to this document benefits you.

\section{Recommended Citation}

Gilbert, Kara Marie, "Youth Voices of Bounty and Opportunity: High School Students' Experiences With Food and Community" (2011). Dissertations and Theses. Paper 302.

https://doi.org/10.15760/etd.302

This Thesis is brought to you for free and open access. It has been accepted for inclusion in Dissertations and Theses by an authorized administrator of PDXScholar. Please contact us if we can make this document more accessible: pdxscholar@pdx.edu. 


\title{
Youth Voices of Bounty and Opportunity: High School Students' Experiences with Food and Community
}

by

Kara Marie Gilbert

A thesis submitted in partial fulfillment of the requirements for the degree of

\author{
Master of Science \\ in \\ Education: \\ Educational Leadership and Policy
}

Thesis Committee:

Dilafruz Williams, Chair

Judy Bluehorse-Skelton

Jonathan Brown

Andy Job

Stephanie Stokamer

Portland State University

(C)2011 


\begin{abstract}
Currently, garden-based research does not include input from young adults about their experiences and perspectives as individuals in garden-based programs, specifically those that address issues of food and community. To address this void, this qualitative research examines youth perspectives and engagement in garden-based community projects in Olympia, Washington, and Medford, Oregon. The sample of 11 students was chosen from these projects that use food as a means to engage the community and educate underprivileged young adults about local food systems.

The main question that the research addresses is: Why, and in what ways, are young adults appropriate agents for community revitalizing garden-based projects? Using open-ended interviews, field notes and observations, the research draws upon theories of food access, community development, social and environmental justice, and nontraditional education. The findings suggest that when young adults are involved in garden-based community projects, they are learning life skills, developing leadership, engaging in models of nontraditional education, and retaining perspectives of grass-roots community development. It is evident from the research and emerging themes that young adults desire to accept responsibility in their community. It is time to harness young people's energy, care, compassion, and dedication so that they can act as ambassadors to dispel the class-based ideologies of the current food systems, empowering underserved communities and celebrating youth's perspectives on food and place.
\end{abstract}




\section{ACKNOWLEDGMENTS}

I would like to first and foremost thank each and every one of the participants in this study. I am blessed to have had the opportunity to engage in heartfelt discussions and to learn from their wisdom as young adults who exemplify the act of putting theory into practice. Food is the engine of their work, and I hope that they continue to challenge the status quo of action and social and environmental stewardship.

Relk Forsloff - for being my partner, my rock, my critic, my confidant, and my best friend.

Family - my four parents: Judy, Jon, Peggy and Howard and my brother, Mike for keeping me grounded and believing in me throughout the process of my wild ideas and perspectives.

Dilafruz Williams - She is more than an advisor and chair; she is an activist and mother to the world of justice and equality.

Jon Brown for his brotherly support and consistently being a sound board throughout my entire journey as a grad student and educator. I would be lost without the countless hours of brainstorming and reflection that we have participated in at the Learning Gardens Lab.

Judy Bluehorse-Skelton, Andy Job, and Stephanie Stokamer for serving on my committee and providing valuable insights support in this process. 
Stephanie Rooney and Jen Anderson - for being empowering women and role models of progressive pedagogy and patience.

Elaine Walker - for ushering me through edits and ideas as we both embrace international perspectives on agriculture and food, and for the countless hours discussing our place as educators and women of the earth, eating well and confronting privilege.

Michael Simington and Jeffery Foreman for the many conversations relating to race and class struggles in society; I feel blessed to have had the critical analysis and sharing of life experiences and trials as young children and adults.

Lane Middle School community and the hundreds of students that I have been blessed to work with and be humbled by - for being the reason I have been empowered and inspired to do this research.

All of the environmental warriors with whom I have discussed and contemplated social and environmental issues, and all of the farmers in the world that have exemplified hard work and service with hands-on approaches to learning and caring for the source of our food. 
TABLE OF CONTENTS

Page

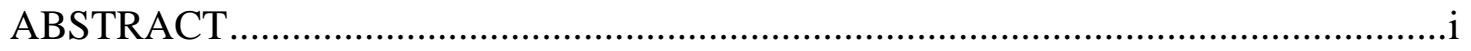

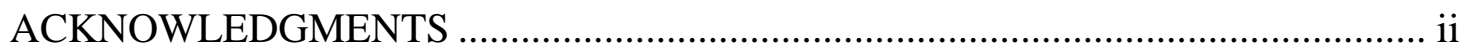

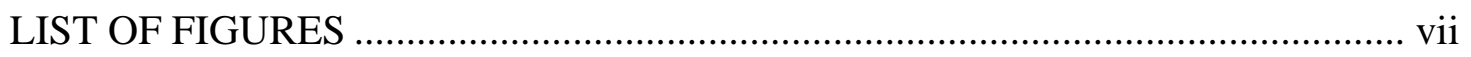

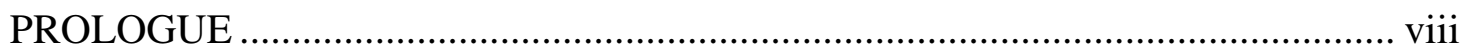

\section{CHAPTER}

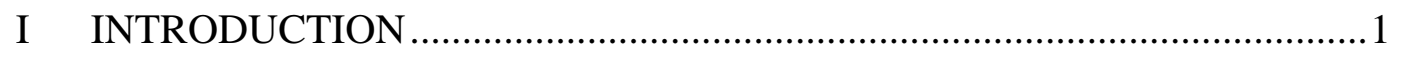

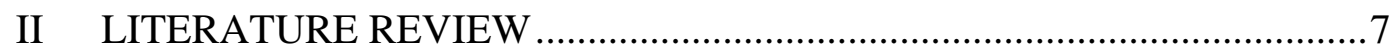

Food as a Basic Need and the Evolution of the Industrial Food Complex .......................................................................................

Community Food Development: Models for Empowering and Working with People for Change .....................................................13

Social and Environmental Justice .........................................................21

Nontraditional Education and Inclusivity .............................................24

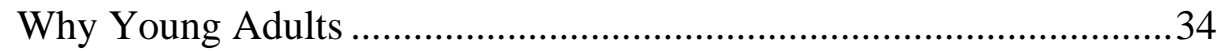

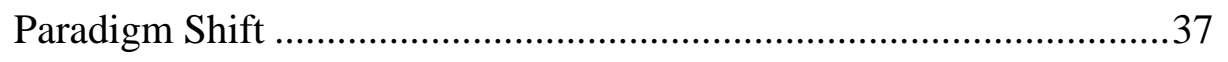

III RESEARCH METHODOLOGY …………………...................................4

Subject Recruitment.......................................................................... 4

Semi-Structured, Narrative-Based Interviews .......................................49 
Field Notes and Observations

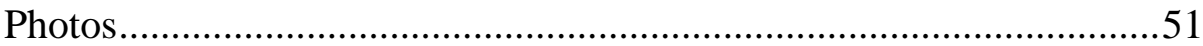

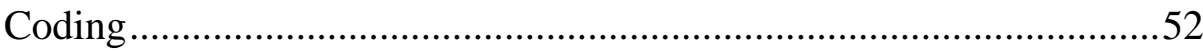

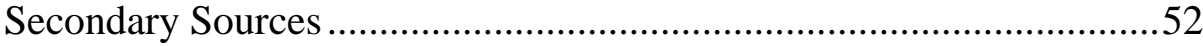

My Role as a Researcher................................................................53

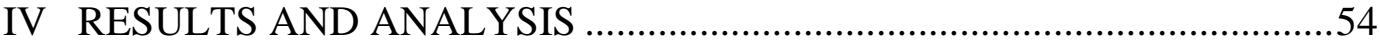

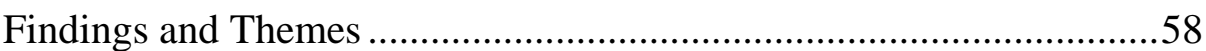

Commitment to Service and Action as Young Adults Alleviate Stereotypes of Young Adults as Lazy Citizens Youth Perspectives on Youth as our Future

Life Skills.

Food and Farming

Stewardship and Responsibility

Service and Action

Leadership

Developing Knowledgebase

Pride and Accomplishment

Hard Work and Confidence

Education

82

Nontraditional Education

Meaningfulness

Skills Oriented

Community Development .88

Social Justice

Care and Compassion

Health and Access

V CONCLUSIONS AND RECOMMENDATIONS.

Conclusions. 


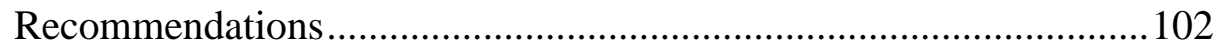

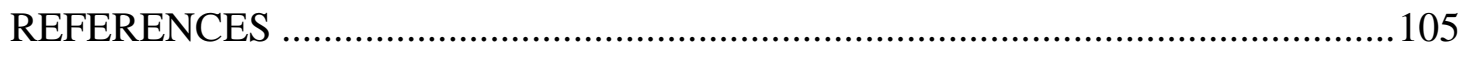

APPENDICES

A INTERVIEW QUESTIONS .............................................................. 112

B FIELD NOTES OUTLINE AND OBSERVATION

CONSIDERATIONS .....................................................................115 


\section{LIST OF FIGURES}

Figure $\quad$ Page

1 Dogwood Illustrating Four Major Findings ...........................................67 


\section{PROLOGUE}

I enter this research with a personal story that illuminates everything that I listen to, write, configure, and process in this research. As a graduate student in the Leadership in Ecology, Culture, and Learning (LECL) Program at Portland State University (PSU), I have researched, discussed, and continuously contemplated how my experience as an educator, gardener, and woman can be put to use in striving to change the world. The LECL program explores nontraditional models of education and pedagogy, supporting the future movement of teaching and learning. Topics examined in the program identify issues such as educators’ power and privilege specific to race/class issues, leadership techniques, and styles. The program also addresses justice and sustainability in relation to social and environmental issues.

For the last 2 years I have worked as a garden-based educator with Lane Middle School, a public school in outer southeast Portland in Oregon. Lane Middle School has a unique partnership with the Learning Gardens Laboratory (LGL), which is located across the street from the school. The LGL has an assortment of gardens that are utilized by multiple classes from Portland State University, Oregon State University, and other local schools in the Portland area. Sixth grade students from Lane Middle School study at LGL 3 days a week as a component of their curricular goals in science and math. As a garden educator I have been able to apply the theories explored in the LECL program in a garden setting with low-income and underserved youth. Moreover, my daily experience has 
illuminated that gardening is a model that I am inspired by and has moved me to integrate social and environmental justice in my life.

As an educator in a garden-based setting at Lane Middle School (LMS), integrating science and math curriculum with garden theory and practical application, I have been fortunate to work with adolescents. The relationship has been a reciprocal one filled with many learning experiences that entail studying the particulars of growing food, celebrating cultural connections, continuously being dirty, working together on numerous projects, and cultivating skills for not only surviving but thriving through growing healthful food; simultaneously, it has challenged traditional education by incorporating multisensory, multidisciplinary, hands-on approaches to learning.

While working with the young children from LMS, I wanted to learn more from young adults in order to better understand their knowledge of growing food and providing for others through community service, as well as to acknowledge and apply these young people's wisdom. As I worked with youth every day with a critical, graduate student lens, I questioned what their relationship might be with the earth and growing food when they are older: Will Marcus still be excited about getting dirty? Will Emmy continue to come each summer and ask countless questions about cucumbers and tomatoes? Will Terrell lose the eagerness to design garden spaces and call it his own?

These questions and many others have inspired me to go deeper by finding participants in programs that empower young adults to better understand the experience of growing food and serving their communities. I wanted to know what young adults had to say about their relationship with the earth, their communities, families, schools, and personal power, and the value in food growing process. 
Food seems most appropriate as a focus of this research for a number of reasons. Food is a basic need of all human beings, and it is something I have been fascinated with given that most of the world lives in scarcity and lacks access to it, while a small minority has an abundance. My fascination for food is influenced by the politics of the global market, the relationship we gain working with the earth and the cultural ties to growing food. Moreover, personally, growing up with the presence of three generations (that included someone living through the depression era), cooking meals with the aroma of food wafting throughout my house my entire life is just another reason for my immense interest in food. I trace my lineage to farmers from Kansas who migrated to the west during the dust bowl and era of the depression, along with my mother's grandparents who made the voyage from Italy in the early 1900s and defined food as their passion and livelihood. 


\section{CHAPTER I}

\section{INTRODUCTION}

In understanding food as a component of inclusive discourse, one needs to conceptualize the daily routine and role that food plays in everyone's lives. When a person wakes up, one of the first inquiries of the day is: what will be for breakfast? In three or four more hours the items of a lunch menu scan through one's mind, and in a handful of five more hours it is dinner time; the routine repeats itself. Regardless if one lives in an alley way or in a mansion, food and the mission to attain the necessary caloric intake for survival are critical. First world citizens take eating food for granted. It is a need for survival like shelter or water. However, class and equity mark major influences in this daily mission. Given that food is the central agent in the allied interests of social activism and equality of change, it is crucial that food inequality is understood and researched in order to promote a forward thinking shift of consciousness in ensuring food access and independence for underprivileged populations.

Berry (2009) has scorned the industrial food complex and the multiple repercussions that have dovetailed throughout history in relation to land and the economy, as well as to the many cultures that have been buried in our history that worked with food for livelihood and subsistence (Nelson, 2008). The paradigm shift that Berry (1987) and Nelson (2008) suggested in eradicating the mechanization of food involves a refined future of land, while regaining a reciprocal relationship with it, ensuring equity 
and sustainability along the way. Berry $(1987,2009)$ has been poetic with his delivery about the evolution of food in American culture and has offered clear sentiments in his literature that support the need for food to be the epicenter of a movement. As he stated, people need to "reconceive the whole problem of health in soil, plant, animal and man as one great subject” (Berry, 2009, p. xi). Food is the nucleus of the future and has been for 10,000 years; facing the issues is imperative. How we relate to food and engage our personal power to grow it, sell it, buy it, consume it, and neglect it will influence the future well-being of the planet and those yearning to live off of it.

As a result of my experience as a garden-based educator and as a firm believer in place-based, hands-on learning, this research is designed to celebrate a garden as a tool for (a) teaching young adults and engaging them in issues associated with food and (b) emphasizing how important it is to work with the land and rely upon something that is outside of themselves. This research also explores food through the lens of social justice, access, and equity. This research listens to young adults' perspectives on the importance of their roles in a food movement and underscores how their experiences in a garden develops their recognition of how their role in a food movement not only enables their personal success but also improves their communities. It reveals the enormous potential for this kind of work to empower young adults to identify issues in their community and develop viable solutions.

Thus, the research is set in two gardens. Each garden is tended to every season with care and compassion. A garden is multidimensional. A garden is not only a place to grow food and celebrate the fruits of hard work and labor; it is a classroom: a place for reflection and passion, an outlet from urban strife and inequalities. A garden is also a 
place to celebrate the diversity of one another as human beings living on the earth, aligning this with the diversity of the natural systems by growing different kinds of foods and celebrating the seasonal variations. Furthermore, it is a tool for social development and community engagement; they are a fusion of environmental and social awareness through growing food, relying upon land, and serving the community while learning life skills.

There is a two-tiered problem with food: access and sustainability. Food access and issues of environmental and social sustainability are important to address because of the large gap in food resources and access (Guthman, 2008; Pothukuchi, 2004; Winne, 2008). Many of those who are involved in food politics are privileged individuals that are unaware of the inequalities that are associated with consumption and distribution of local fresh foods. Food that is consumed in low-income, underserved areas and neighborhoods tends to be unhealthy due to access and privilege (Guthman, Raskin, \& Short, 2007). Healthy food is not at the forefront of community development; therefore, this is the time to confront the corporate food system and empower communities to learn about the issues that are associated with access and power relations. Indeed, I believe that young adults can be the active agents to effect these changes.

Young adults are often neglected or dismissed as consultants about issues and problems that exist in society, specifically regarding environmental and social sustainability. Not only are young adults generally on the margin of social and environmental activism, those that are involved are rarely consulted about their experiences. However, young adults engaged in projects that inspire real-world issues 
have unique and insightful perspectives to share, which can provide a lens for future discourse and programming to empower them as active participants in discussion.

Thus, the research I have conducted is designed to explore the themes of equity, justice, social sustainability, youth, community engagement, and place-based learning in a garden setting with young adults as the voice leading the dialogue. Currently, gardenbased research is not inclusive in seeking input from young adults about their experience and perspective as individuals in garden-based programs. I believe that the voices of young adults need to be heard and understood as a valid foundation for future programming, which will alleviate class-based issues associated with food and access. Understanding what socially and environmentally engages low-income young adults toward a path of success is critical for long-term sustainability (Jones, 2008). I use gardening as a medium to fuse my experience as a researcher and garden-based educator with theory and conceptual knowledge of empowering learners in place-based, nontraditional models of education.

The main question that I intend to focus on in this study is why, and in what ways, are young adults appropriate agents for community revitalizing, garden-based projects? To arrive at answers, I am also interested in the following questions:

- How does a garden-based community project serve participants active in the project as well as in the greater community?

- How does a garden-based program engage young adults in topics of social justice and equity?

- Does garden-based learning promote environmental stewardship amongst participants? 
- What motivates young people to sustain a long-term garden project?

- What models of pedagogy are appropriate for young adults in regards to social and environmental knowledge?

There are multiple organizations in this country that engage the principles that are critical for this analysis. I have chosen to explore the Garden Raised Bounty (GRuB) Program in Olympia, Washington and the Medford Opportunity High School’s Job Council in Medford, Oregon. Given location, seasonal influences, and time constraints, both Garden Raised Bounty and the Medford High School’s Job Council allow me to undertake in-depth research. Each organization differs in its modalities, but both share a common age/class demographic, employment structure and monetary compensation and an alternative, holistic mission of education and food security.

I have chosen both of these organizations because of their missions to serve underserved students and the local community through providing an environment that practices nontraditional tangible, hands-on, and inter-disciplinary pedagogy with gardenbased learning as the driver and catalyst of engagement. My interviews include the insights from 11 young high school age participants: 4 males and 7 females, 5 white, 4 Latino, and 2 African-American. This sample seeks to capture the existing diversity, as well as comprehensively represent and give voice to each of these demographics.

Overall, my investigative research seeks to present understandings that explore the intersection between the three major themes of equity, place-based learning, and garden-based education by looking at youth engagement and social justice via the means of food access. 
The following chapters are designed to guide the reader through my research and better understand the importance of youth advocacy and the vital role that it plays in the food justice movement. Chapter 2 presents an analysis of the intellectual ancestors that have provided a foundation for the major themes and theories explored in the research. I have organized this chapter in sections to illustrate the many themes and theories that I have used in conceptualizing the larger ideas associated with underserved young adults and the food movement. Chapter 3 describes the methodology used to conduct the research. This chapter details how I interviewed young adults and asked them a series of questions about their experience in youth led food projects. It also explains my rationale for additional techniques including field notes, secondary sources, and coding. Chapter 4 analyzes my results and findings from the interviews and field notes. I have organized the chapter into sections that outline the four major themes and topics that are found to be consistent in the responses of the participants interviewed. The themes are: life skills, leadership, education, and community development. Within these themes I have identified sub-topics that are specific to the voices and responses that emerged form the interviews and site visits. Lastly, chapter 5 presents suggestions for similar future programs for youth-led food projects that will advance their success in order to effect greater change. 


\section{CHAPTER II}

\section{LITERATURE REVIEW}

\section{Food as a Basic Need and the Evolution of the Industrial Food Complex}

The choices of unhealthy foods, which have confined young adults, are affecting

the health of Americans, specifically the underprivileged population. In turn, society fails to associate issues of hunger with academic achievement and the deflation of personal leadership.

Approximately 17 percent of American children live in households defined as food insecure, that is, the families face difficulty providing enough food for all its members due to a lack of resources... [leading directly to] lower grades, especially in reading, math, social studies, and science; poorer attendance; higher rates of tardiness; and more behavior problems than children not at nutritional risk. (Coles, 2009, pp. 34-36)

For the plethora of reasons identified, people (specifically young adults) need to understand food systems and how they can be changed to mediate the poor health standards and accessibility of food in urban and rural populations.

Access is a primary reason for the discrepancy between those who eat well and those who do not. Winne (2008) has worked on the East Coast identifying issues of food insecurity and community development strategies to curb the gap in food access. In one study he found the problematic reality that "chain supermarkets were four times more likely to be located in predominantly white neighborhoods than in black neighborhoods” (p. 88). Food, when understood as a class issue, propels critical inquiry amongst multiple 
other topics that address inequality. In turn, as Glickman (as cited in Winne, 2008) from the United States Department of Agriculture stated:

Restricted or limited food access undermines the USDA's ability to promote health through nutrition, because if prices are too high, there is not enough bang for the buck for Food Stamps and WIC (women, infants, and children), or if choices are limited... [Americans] can't make the choices that nutrition education efforts encourage them to make. (p. 89)

With the difficulties assembled in government assistance programs, accompanied by the reality of lack of local grocers selling healthy food in high-risk areas, disenfranchised consumers face an uphill battle with limited options. Because the social communities embracing and developing the healthy food movement have generally been composed of white, upper-class individuals (typically those who do not live in the inner city), advocacy for greater food access and choice in poor, often minority, urban neighborhoods has preserved limited options in these areas. The lack of and/or the access to fresh, locally grown food in underserved areas is surfacing because of multiple social and economic implications. For example:

In times of severe political or economic crisis, when supply lines or currencies collapse, large cities are particularly vulnerable to food shortages. Increased urban food production is in many cases a response to this problem. (Lang \& Millstones, 2008, p. 54)

Similar to the literature of Lang and Milestones (2008), Fahmy (2006) discussed the role of social capital and how influential it is to mobility and action in regards to the urban food movement:

Although the inner-city is typically characterized as being without social capital, many people rely on social ties for economic survival though these assets may be insufficient to enable people to escape poverty. (Fahmy, 2006, p. 104) 
Robbins' (1987) theory of food and consumer choice is an assortment of facts and figures that relate not only to what we eat and how it influences our health and well being but how it simultaneously manipulates the planet’s flora and fauna. While Robbins educated the reader in the health and politics of what one eats, he ignored the social implications of who can and cannot buy and live the lifestyle that comprises privileged consumer choice. He focused plainly on animal rights and health related to food choices. Other scholars, such as Campbell (2004), Guthman (2008), Pothukuchi (2004) have integrated social rights and access at the forefront of development. Many reasons influence why and how we consume. Once people understand their patterns of consumption and sources of food, issues of justice and sustainability surface. In The Omnivore's Dilemma, Pollan (2006) wrote about consumer choice and the abrupt abduction into processed foods with patterns that evolve into malnutrition and unhealthy lifestyles. Pollan stated:

The power in food science lies in its ability to break foods down into their nutrient parts and then re-assemble them in specific ways that, in effect, push our evolutionary button, fooling the omnivore's inherited food selection system. (p. 107)

The people that have been most manipulated by cost to consume low quality, high fat, sugary foods are the underprivileged people in this country. The once understood concept of food and where it comes from has been replaced with McDonalds and 7-11 convenient stores packed with unhealthy, processed foods.

In the past decade, a multitude of scholars, critics and ancestors have illuminated food politics with precise consideration of the environmental, social, and economic costs that are affiliated with consumption. This is something that the mainstream culture has 
neglected showcasing until recently. Growing food (and understanding food) promotes personal responsibility and environmental stewardship all while meeting the basic needs of human existence (Jones, 2008; Nelson, 2008; Winne, 2008). The choices that we make as consumers have implications and repercussions, as Singer and Mason (2006) noted in their research on families and the moral ramifications of buying, consuming, and growing food. Many social structures and consumer habits need to be reevaluated to close the gap of access and accountability.

The open dialogue and education mentioned binds the urban and the rural in relation to food and politics. There is the potential for a future in which people and social structures have "more tolerance for differences, less emphasis on materialism, where people value creativity and are interested in working on issues related to peace and justice [regarding food]" (Singer \& Mason, 2006, p. 196). In turn, "local farmers are willing to talk to you about your concerns and to show their methods and systems” (Singer \& Mason, 2006, p. 286) in relation to where and why our food is grown locally. In order for shared methodology and ideology to surface, more people from multiple social classes and geographical environments need to be engaged for real life in-depth outcomes to shape how and where we go next in food policy and change (Wekerle, 2004; Winne, 2008; Wynne, 2006).

Singer and Mason (2006), food scholars and critiques of consumer choice, have suggested that society has forgotten the debt that their choices have on the planet, people, and the economic trade system. Singer and Mason have clearly stated that when people consider food ethically, they are compelled to face their choices and personal morals in regards to food. They studied families from different social classes and lifestyles and 
showed how consuming food resulted from subjects' personal situations and access to information. They also showed how the overall culture and economic standing enables one to buy or not buy organic, fresh, and locally-based products. While Singer and Mason illustrated the choices and influence people have on food production and quality of the human and non-human environment, many authors have noted that food production needs to be at the home-front with individual people growing and maintaining a garden or any edible space to reestablish relationships with food and its sources (Kingsolver, 2007; Nelson, 2008; Shiva, 2005).

Kingsolver (2007), a critically acclaimed author and environmental steward, spent a year of her life living off the land, incorporating not only techniques and lifestyle choices of sustainability but community and familial ties that stemmed from cultivating food and regaining relationship with the land. Kingsolver stated from her experience that the "main barrier standing between ourselves and a local-food culture is not price, but attitude. The difficult requirements are patience and a pinch of restraint-virtues that are hardly the property of the wealthy” (p. 31). The attitude that she mentioned is the gift that working with the land had given her and her family. She provided suggestions, recipes and noted that multiple families and people can adopt regardless of social status or access. The potential for this to manifest rests in the future of schools, families, inner-city dwellings of concrete and stone, backyards, and playing fields. Kingsolver stated:

We set upon a journey. It seemed so ordinary on the face of things, to try to do what nearly all people used to do without a second thought. But the trip surprised you many times, because of all the ways a landscape can center one's physical being. (p. 335) 
The skills obtained in urban agriculture projects have a multitude of positive effects on those participating: academic scores rise, not only because of engagement, but also due to the valuable nutrition that is available when young adults are working with whole foods. Kingsolver emphasized the inherent connection of working with the earth and getting back to the land (a connection most cultures have marked as foundational for thousands of years), the importance of life style changes and the voice of historical movements encouraging pastoral livelihood, cultural celebration, and environmental stewardship.

The movement of growing food and rekindling a relationship with land and space is gaining momentum and can be seen in the exponential increase in school gardens, home gardens, church and community gardens, and large-scale agricultural projects. The earth is an entity that initiates success in learning about one's self and the planet, which is relied upon for subsistence (Kaplan, 1973; Klindienst, 2006). Numerous school related environmental outreach and sustainability programs are making strides to build upon issues of equality and justice through a theoretical stance of environmental responsibility, stewardship, and relationship to place - all while growing food. These resources are also important to bridge other allied organizations and programs that value growing food and working together as communities.

Cultural awareness undoubtedly surfaces when working with land and growing food. With their inherent ecophilia (Louv, 2005), people start to explore a relationship with the natural environment, along with historical and place-based identities. Klindienst (2006) has explored the relationships that people obtain with land cultivating food in this country. We are a diverse community of people, places, and food. In The Earth Knows My Name, Klindienst shared more than 15 stories of food, culture, and place from all 
across the United States. These diverse stories emphasize that "food has a form of deep cultural memory, food has a source of sustenance that answers man's hungers - for beauty, for connection to a place, for a sense of community” (Klindienst, 2006, p. xxii). Many cultures and people have immigrated here with a skill-base of farming and agriculture; instead of exploiting people and their history in this country with mechanistic systems and relationships with food, the space exists to celebrate and honor one’s ethnic origins. Farming and gardening are ways to retain the relationships that bloom from being outside, growing food, and working with different people toward the same goal. Young people are the missing links between culture and place. They deserve to regain their sense of place and time as leaders in change and food security and access.

\section{Community Food Development: Models for Empowering and Working with People for Change}

Models of community revitalization and development typically include neighborhood associations, parent organizations, and other community action groups that address issues of community instability and concerns regarding environmental, social, and economic structures that influence a community and their success (Chambers, 2007; Smock, 2004). Ineffective development leads to deprivation and lack of basic needs, which directly affects local people at the local level, more often than not, those that are initially underserved in the system. Leaders in the community development movement need to address the economic, societal, and environmental relationships in communities in order for a structural shift of equity and sustainability (Brown, 2009; Chambers, 2007). The majority of community groups and change makers are adults and those who are invested in an evolution of change in their communities (Smock, 2004), yet successful 
movements harness the energy and charisma of an inter-generational audience that encourages long term sustainability (Saunders, 2006; Youniss \& Yates, 1997). Identifying historical contexts of community development, along with successful movements in high risk areas, will provide a base for understanding why civic engagement and civic agriculture movements are important models in which young adults are integral as proposed leaders in the discourse of eradicating food deserts (Winne, 2008), areas that are equipped with only corner stores and liquor stores for grocery options with little to no fresh food within miles, and reclaiming space in urban and rural environments.

Developmental models that have been effective historically are those that involve the local community at the ground level through the experience of working toward a set of shared goals (Smock, 2004). Many theorists who have worked with people at the local level for change have stated that building individual capacity will, in turn, build a strong community. For example, Smock (2004), an elder in community organizing, stated that, "the development of the skilled, self-confident civic leader who can play an active role in public life is an essential prerequisite for a strong democracy” (p. 38). Shifts in consciousness and power are difficult because power is viewed as a negative trait. Power is not inherently negative; it is how one uses power for change that matters. Alinsky (1971) presented a balance of ideas and components of democracy. In Alinsky's (1971) literature on radical movements and the role of a leader, he stated that:

The corruption of power is not in power, but in ourselves [as leaders]. It is the power of active citizen participation pulsing upward, providing a unified strength for a common purpose. The power of a gun may be used to enforce slavery, or to achieve freedom. (p. 51) 
The power identified here is what runs the engine of change and action of a community project. With power comes self-interest, compromise, ego, and conflict (Alinsky, 1971), all threading the net of action in developmental leadership and change in an underprivileged, often disjointed community.

It is pertinent to identify historical movements and the specific strategies they employed that resulted in progress and real change; reinventing the wheel is unappealing for direct action and mobility (Polak, 2009). Rooney's (1995) literature on the organization of the South Bronx greatly informs what primary and secondary causes led to the collapse of a once vital, urban space. In light of urban change and development, one has to address the causes and effects of collapse to learn from history and pave a productive path into the future. The primary causes that Rooney identified as to why the South Bronx collapsed are: (a) disappearance of jobs, (b) government policies, and (c) failure of leadership. Beneath the primary causes were institutional disparities that echoed across the landscape of Brooklyn and the impoverished community. Rooney identified the role of racism, landlord and tenant arson, fear of crime, and specific city development practices of expressways and construction as secondary causes. These secondary causes alienate poor people from mobilizing. The primary and secondary causes Rooney identified are the same issues that are hindering food justice movements and action today. Specifically, with youth movements, there has been a lack of cultural capital that motivates young people to mobilize and take action (Fahmy, 2006; Youniss \& Yates, 1997). Wilson's (1996) findings on urban-underclass citizens in regards to their behaviors and social structures showcased a need to be resistant. For example, Wilson's research suggested: 
The social interaction among neighbors tends to be confined to those whose skills, styles, orientations, and habits are not as conducive to promoting positive social outcomes (academic success, pro-social behavior, etc.)... although close interactions among neighbors in such areas may be useful in devising strategies, disseminating information, and developing styles of behavior that are helpful in a ghetto milieu. (p. 63)

Alinsky (1971), Rooney (1995), and Smock (2004) would each argue that with the skillbase and leadership from organizers and community members, these characteristics have the potential to be dissipated. Capacity building (Smock, 2004) and relational organizing (Rooney, 1995) motivates people to change their perspectives of power while working with others for a similar end goal of justice and community revitalization.

Development is complex and weighted in overarching societal issues. An organized attempt in planning and developing a strong knowledge base is needed before tackling something as critical as food and accessibility. Pothukuchi’s (2004) work focused on community food assessments and how the methodology of development and practice integrates leadership and evaluation. He offered that:

Community food security is scarcely intended as a replacement for federal entitlement programs aiming at poor and vulnerable residents. Rather, it is an approach that seeks to increase community influence on these systems, to offer an integrated view of the links within the food system and between food and communities, and to provide more sustainable alternatives to current streams. Community food security advocates are finding that building partnerships with relevant public agencies and community-based organizations and coordinating efforts is essential to developing effective and lasting solutions. (p. 360)

Wekerle’s (2004) perspective of food justice explored “the implications of focusing on food security as a social movement and the relevance for planning and urban theory” (p. 378). Wekerle initiated a platform for discussing food justice, that entails reviewing and understanding multiple theories and critiques of past practice involving 
food in order to move forward and find alternatives to the unjust practices that affect people all over the world.

Food justice and issues of food security are interactive processes that take survey and analysis, capacity building, and grass roots organization to be understood, as well as be productive and sustainable. Wekerle (2004) declared that:

Food justice movements, as place-based movements engaged in local organizing and community development, represent an engaged citizenry that should be of interest to urban planners focused on various forms of citizen planning. (p. 379)

Guthman et al. (2007) studied and evaluated food issues in the San Francisco Bay Area, rekindling what many of the other theorists pointed at in their studies. These three researchers were very specific to the population and ground work that had to be done in order for people to have access to "culturally acceptable, nutritionally adequate food through local non-emergency sources” (Guthman et al., 2007, p. 354). The idea that stemmed from the study was that high-risk communities, those similar to Rooney's (1995) work in the Bronx, are living in impoverished areas known as food deserts. In this study, it was crucial to understand the reasons for the abundance or scarcity of food security, such as "accessibility, affordability, nutritional adequacy, and quality of food" (Guthman et al., 2007, pp. 356-357). The research presented illustrates that the foundational principles of access need to be identified to engender change.

Farm-to-school programs are also productive measures that can drive change in communities and food security at a local school-based level. As Vallianatos, Gottlieb, and Haase (2004) acknowledged, "Farm-to-school programs, like CSA [for example] in the classroom, can play a role in influencing food choices, including for low-income students and adults who have limited access to sources of fresh food” (p. 415). Models 
that integrate accessibility in development, with multidisciplinary approaches to fresh food, create "healthier school food [that can] help address dietary factors related to the rise in obesity, early onset diabetes, and other diet-related conditions that have become major health risks for America’s youth” (p. 415). Holistic developmental strategies reach beyond the problem at the surface and include the deeper issues that are associated with fresh food and accessibility. In the United States there are multiple programs that work with all ages in promoting healthy life styles and personal power in growing food and feeding their communities. There are cutting-edge, youth-led programs that work on revitalizing low-income areas with garden projects all over the country. Researching and learning from the specific milieus and curricular goals is imperative.

With food as a lens in striving for community-development and change, appropriate networks will need to be initiated for action to occur. Civic engagement and social capital are pertinent traits and resources for change at a community based level. Schneider (2007) distinguished the positive and negative components for both that can be integrated into how a community moves forward. Civic agriculture and engagement theorists have identified food as an agent for development and revitalization in lowerincome communities. Civic-agriculture, as defined by Wynne (2006):

...refers to the emergence and growth of community-based agriculture and food production activities that not only meet consumer demands for fresh, safe and locally produced foods, but create jobs, encourage entrepreneurship and strengthen community identity. (p. 226)

This civic-agriculture theory encompasses the basic needs and elements of sustainability including the environment, society, and economy. The health of a community is ultimately determined by whether or not basic needs are being met. Food 
as a basic need is essential for developers and organizers to recognize for progressive measures to empower underserved members of society because rich "civic health" is a “tool for repair” (Wynne, 2006, p. 226). Wynne (2006) concluded that civic agriculture and motivating people to stand up for social responsibility in agricultural development will revitalize engagement by inspiring further leadership and mobility, extending beyond the discourse of inclusivity to the "broader social forces in which it [food] was produced" (p. 230). Wynne’s model is multidisciplinary for an all-encompassing approach to community education and social sustainability. Schneider (2007) similarly identified the positive approaches to civic engagement and social capital similarly but without food as the driver.

Schneider (2007), Wynne (2006), and Smock (2004) noted that activities pertaining to civic engagement and social capital motivate participants to work together for the "common good" (Schneider, 2007, p. 573). The common good associates with the needs and wants of the individual, as well as for the greater needs of society, which evolve from issue to issue within the scope of a project. Many of the case studies that Schneider examined gathered citizens throughout the community in bonds of solidarity to improve the quality of life for low-income residents with an enforceable trust that enabled people and institutions to gain access to resources. The theories of social capital and civic engagement are seen as being similar as they are different in meaning by Schneider and other academics. As noted by Schneider, social capital in time evolves into avenues for civic engagement, although not in the same scope and practice in different communities. Civic engagement inspires people to use the skills obtained from their 
social capital, to inspire change for the overall good of the greater community (Schneider, 2007).

Civic agriculture is another component of this research that links the characterizations of social capital and civic engagement with a movement of food development, necessary access and community integrity. Because development is a difficult process, and food disparities are some of the highest, planning committees and developers need to look at the "epistemological, political and institutional, socioeconomic, spatial, community, and organizational levels” (Campbell, 2004, p. 341) that aggregate change. Food insecurity is an issue at both the local and global level, and class disparities are influential in determining who is affected most and who is living in areas identified as food deserts. This inequality is due to what Campbell (2004) claimed in regards to people, "see[ing] food as an individual and community right rather than a commodity or an entitlement” (p. 346), and action must take place in order for community residents and members to evolve from "food consumers to food citizens" (p. 348). The facts Campbell shared are overwhelming yet critical to understanding the skill-base and theories that are necessary for development to focus on food rights and access. "If you build it they will come” (Guthman et al., 2007, p. 63) is a huge point because people are vulnerable and in need of their basic needs and accessibility. However, because there are a diverse range of indicators as described above, there is concern that:

If a focus on access has emerged simply because it represents the clearest or easiest path to action, even if in keeping with prevailing ideas of economic development, it may not embody a range of alternatives sufficiently diverse and flexible to resolve a problem as complex as urban food security. (Guthman et al., 2007, p. 363) 
Identifying food security and civic engagement theories as tools for action is important because it involves a basic human need that everyone can relate to: nourishment and survival. Food does not merely focus on social and environmental disparities, but it enables an economic stability that can be reached with less reliance on imported goods. Giving young people the power to grow food, sell food, and teach their communities about issues pertaining to food justice and sustainability will catalyze shifts on all levels of environmental, social and economic stages of community security.

\section{Social and Environmental Justice}

Justice is a term that many academics use when class and power issues arise. Justice must be reflected upon and integrated throughout different perspectives and life experiences in order for people to take ownership and create change. Shiva (2005) used the term justice in relation to the democratic necessity for inclusion of all living things and communities that encompass the earth, "consisting of all beings and humans of all colors, beliefs, classes and countries” (p. 2). Globalization and market-based economies have neglected the importance of the commons (Shiva, 2005) and the power of "real people, exchanging what they create and what they need, [while being] replaced by the abstract and invisible hand of the market” (Shiva, 2005, p. 18). So often the replacement by capitalistic ideals and powers that Shiva argued displaces marginalized, low-income communities and offers no alternative for basic needs and resources; ultimately this completely removes them - from the discourse of change and reform - illustrating unjust relations and behaviors. In addition to the aforementioned research, a great deal of literature exists that focuses on community projects related to environmental justice 
action networks and organizations structured around social rights and justice, specifically in low-income, marginalized communities.

Chambers (2007) wrote extensively about minority empowerment and environmental justice; she specifically addressed ways in which people of color have integrated themselves in environmental movements and why and how they have been successful in making change and empowering people to fight for justice and inequality. Historically, as she stated, minority empowerment "focuses on protest and electoral strategies” (p. 29), while environmental justice groups are troubled with “electoral outcomes as a strategy for affecting environmental policy” (p. 29). Moreover, environmental justice groups are concerned with why and how policies are influencing their communities. Their tactics in social mobility have made an impact by negating their marginalized role in society.

Chambers' (2007) research on the Hartford Environmental Justice Network (HEJN) described tactics that led to enormous success in fighting for the social and environmental sustainability of Hartford. HEJN benefitted most from strategies that engaged the community in reclaiming their power and leadership for rights associated with land use and proximity to low-income housing areas. HEJN's strategies included multiracial and minority roles in organizational leadership and retaining community ties that protect community members in other aspects of life, for example: churches, and school organizations. Environmental justice hinges on the foundations of social justice, although the difference is in how people understand their role and influence for change amongst communities. 
Tso and Hill (2006) highlighted the necessity of relating environmental stewardship with issues that were local in the lives of the community because (specifically with older youth), "organizations can significantly increase their impact by linking their activities to ones that have a clear social justice implication and focus youth on taking leadership to correct inequalities found in their community” (p. 9). Tso and Hill discussed the role that members of a community can adopt, specifically with youth, in dissolving inequalities associated with social and environmental issues. Tso and Hill defined the principles of environmental justice and the role of access to all people as follows:

The principles of Environmental Justice mandate balanced and responsible uses of land and resources, and affirm a fundamental right to clean air, land, water and food. Access to urban green space and quality environmental education comparable to communities with more wealth and resources establishes progress toward environmental justice. (p. 16)

There are clear examples of how using a common language to educate participants in critically thinking about issues that effect their lives will, in turn, instigate change and empowerment. Given that there are societal threats to justice in multiple communities, environmental justice is a consolidating motive for mitigating both social and environmental issues simultaneously. Jones (2008) married the discourse of social and environmental justice well with the Green Collar Economy model, stating that:

It is important that we wrestle with these questions consciously and openly-before the greening of the world's economies proceeds irretrievably along the same lines as the unjust, unequal, gray economies...everyone must be allowed to share equitability in the benefits and the burdens, the risks and the rewards of our transition to a more survivable economic [socially and environmentally sound] system. (pp. 72-73) 
Currently, the social and environmental justice movement strives to involve food issues and the unscripted politics of access regardless of race, class, or gender that is addressed by many authors in this review. However, so many of the issues that involve environmental and social activism in areas of distress indicate why food distribution and access are a problem. There is a fine line of focusing solely on food, which is why youth led programs that are successful in promoting food issues and issues of foundational social and economic tension are multidisciplinary and inclusive of real world ideas that harness life skills.

\section{Nontraditional Education and Inclusivity}

In The Pedagogy of the Oppressed, Freire (1970) emphasized the necessity to step back as an educator and reconfigure and propose a shift in educational approaches that dissolve the industrialized model of education. He suggested that educators and learners share the experience and learn from one another in the process. Education is a process comprise of teacher and learners interacting and sharing ideas within inclusive measures of learning. There are multiple models that harbor his theory and mission to reinvent education and progressive pedagogy. Multicultural education, garden-based education, outdoor programming, place based, and other models of nontraditional pedagogy have been identified as productive, working models in education that empower young adults as learners. To understand the models mentioned and why there has been a shift toward nontraditional learning environments, one has to understand how the school system evolved and dismantled the rights and prospects of young students.

The social threats to the school system are most important to understand, for this relationship is what propels change in environmental stewardship and programs that 
honor the rights of the human and natural non-human environments for models of remediation (Jones, 2008). Kozol (1991) wrote at length about the inequalities of the school system, highlighting the racism and unequal opportunities that the younger generations in this country are subjected to daily. Kozol, in a series of questions, inquired as to why the inequalities exist and why schools are ill preparing the future of leadership and equality. When discussing North Lawndale School located in the South Side of Chicago, Kozol described the current situation:

One searches for some way to understand why a society as rich and, frequently, as generous as ours would leave these children in their penury and squalor for so long - and with so little public indignation. Is this just a strange mistake of history? Is it an American anomaly? Even if the destitution and the racial segregation and the toxic dangers of the air and soil cannot be immediately addressed, why it is that we can't at least pour vast amounts of money, ingenuity and talent into public education for these children? (p. 40)

Delpit’s (2006) literature echoed Kozol’s (1991) sentiments in its fight to educate readers about the injustices of the school system by identifying problems that the mainstream media intentionally hides or ignorantly neglects in its coverage of the urban education system. By relating the catastrophe of New Orleans to the education system, Delpit emphasized the gravity of the inequalities:

One of the changes that carry the most weight for all of us is the realization that we are not the country we once believed ourselves to be. The horror of nature's attack on major city [New Orleans] has been overshadowed by the distorted attitudes towards those that are darker and poorer. (p. xii)

Delpit's connections are critical in establishing a new paradigm and pedagogical approach to education and learning in this country's school system. Traditional schoolbased approaches have not been successful. As Deutsch and Jones (2008) have declared:

Youth are striving to individuate from adults while also retaining supportive ties. This occurs concurrently when a school experience in which teachers are often 
exerting greater control, leading to a mis-match between students' development need to autonomy and closeness and a school environment which is larger, less personal and more regulatory. (p. 670)

Noddings (1992) introduced the ethics of care as a model of progressive pedagogy aimed at understanding young adolescents as competent individuals deserving of an educational environment of care, not competition. The ethics of care model includes the supportive ties that Deutsch and Jones (2008) described in the above quote. Noddings discussed the potential for education and youth-centered philosophy, honoring the centers of care, which she explained as:

Care for the self, for intimate others, for associates and acquaintances, for distant others, for non-human animals, for plants and the physical environment, for the human made world of objects and instruments, and for ideas. (p. xiii)

Youth led movements involve the cultural, historical, and psychological needs of young adults, along with the ultimate needs of reciprocity of caring relationships as leaders and learners for progressive change. Noddings (1992) challenged traditional approaches to learning and encourages teachers to reach beyond class-based theory of how students learn by sympathizing with their needs and developing purposeful, selfless learning environments. Understanding the ethics of care (those cared-for and those that care) is an important element of this research because it theorizes multidisciplinary approaches to learning and teaching with care as the centerpiece, which is a prerequisite for a successful learning environment.

Multicultural education and non-western ways of learning provide several theories that bring social and environmental issues related to care of the earth and care for the self together into curricular goals in negotiation of dichotomous relationships (Freire, 1970) between the student and the teacher. The multicultural approach to education 
breaks from the traditional model of the education system in both practice and curricular theory (Marouli, 2002; Nelson, 2008; Orr, 2002). Because the learners may be from an array of cultural backgrounds, creating a space for multidisciplinary learning environments provides a platform where students are successful and enabled to succeed (Marouli, 2002; Pelo, 2009; Pusch, 1981; Sterling, 2001). Pusch (1981) shared that:

To understand cultural relativity is to recognize that different cultures provide different behavioral options for satisfying the universal physical and psychological needs of Homo Sapiens. This understanding lays the foundation for a kind of cultural literacy, the acceptance of man as a cultural being. (p. 63)

Marouli (2002) has suggested that for forward thinking sustainable ideals to surface among the general public, programs must be established that involve multicultural models of pedagogy including diverse populations while "understanding, respecting, and utilizing their perspectives in environmental education” (Marouli, 2002, p. 28). Programs are most often successful when they maintain an interest in local community needs and rehabilitation by the stakeholders involved (hooks, 2003; Jones, 2008; Tso \& Hill, 2006). Leadership development and community capacity have a strong hold in establishing a platform for people to feel comfortable and willing to reach out politically in regards to environmental justice and issues of sustainability (Smock, 2004).

In order for youth projects to reach environmental and social arenas, programs must accommodate both the needs of the community and the consideration of the nonhuman environment, simultaneously helping students in identifying how "their own actions can contribute to a sustainable future” (Fien, 2000, p. 5). Fien's (2000) research involved youth and their attitudes about environmental issues and conceptualization of sustainable content. Conclusions clearly indicate that the attitudes of young adults in 
relation to environmental issues have evolved and that there are precursors as to why they have or why they have not been engaged previously: Environmental issues are rather daunting and difficult to engage in. Fien has asked:

Are students' misunderstandings due to incomplete teaching, inadequate educational resources or, perhaps, the tendency for environmental courses to focus on problems rather than solutions and success stories? (p. 4)

When addressing issues that are related, yet very objective, it is difficult to feel as if one person has enough power to change an issue or topic. Fien concluded that pedagogy needs to change:

Unbalanced priorities calls for a reaffirmation of the role of formal education in building civil society by helping students: (i) develop criteria for determining what is best to conserve in their cultural, economic and natural heritage; (ii) discern values and strategies for creating sustainability in their local communities; and (iii) their understanding so formed, with others, to national and global contexts. (p. 8)

This is a competence that Orr (1992) suggested regarding citizenry and the unwavering commitment that institutions should foster in order for evolution to take place and people (specifically young adults) to become active, engaged, and informed in the discourse of change and social competency.

The evolution of environmentally inclusive pedagogy is the foundation that Marouli (2002) suggested in accommodating a learning environment that is culturally safe and engaging for a diverse audience of learners. Marouli proposed that in order to weave human and non-human environmental needs, it is important to "highlight the close relationship between social inequalities and environmental degradation...aim [ing] toward environmental rights for all, including oppressed groups” (p. 32). The connection Marouli discussed in multicultural environmental education theory is a process. Access is 
the point at which many people have been excluded from the topic of environmental issues; society has suggested that they play an insignificant role in change (Taylor, as cited in Marouli, 2002). Marouli quoted multicultural educator Running Grass in her discussion about cultural diversity and its relativity to multicultural education, concluding from his wisdom that, "exposure to and respect of cultural diversity, environmental justice, a constructivist pedagogy, and community involvement are significant components of multicultural education...concern [ing] the process” (p. 29), of understanding and knowing which can break down societal models of power and privilege. Given that the urban populous has been disjointed in relation to the natural environment, steps need to be taken to identify and understand by exploring, "what exists of the natural world in their neighborhoods” (Pelo, 2009, p. 32).

To foster an intimate relationship with place [natural environment], we need to know the stories and histories that are linked to that place, just as we do in our intimate relationships with people. (Pelo, 2009, p. 34)

From place-based inquiry, programs can be set up that progress toward an evolution in benefitting the human and non-human community, offering inclusive discourse (Fien, 2000; Hale, Snow-Gerono, \& Morales, 2008; Jones, 2008; Shiva, 2005). Experimentation and hands-on inquiry enable learners to explore and become part of the environment in which they are studying and seeking to understand. Tso and Hill's (2006) research on education and cultural competency in experiential environmental programs parallels multiple ideas and models that have been suggested by Marouli (2002), Fien (2000) and other intellectuals on the subject. In their research, education involved the entire community in empowering the younger children and adults, as well as piloting an integration of environmental stewardship to the culture of the community. 
They can take these actions even further by getting their neighbors involved...[it] can happen when city residents are aware of and are encouraged to explore and enjoy their environment, have a strong sense of belonging and ownership of their communities, gain an understanding of how their individual actions affect the environment, and are equipped with the skills to make informed decisions and take action is necessary. (Tso \& Hill, 2006, p. 3)

The Experiential Environmental Education program that Tso and Hill (2006) researched, aims at "engaging youth in science and the environment, and stimulating youth to care about and become active stewards in protecting their local environment” (p. 1). This mission statement strives to engage the greater community by empowering them, specifically where the participating students live, in order to remain inclusive and oriented to the needs of the local people.

Youth empowerment and leadership organizations, vocational training and urban sustainability programs, and organizations that focus on environmental issues and equality have begun to face multicultural perspectives in education and development with, "exposure to and respect of cultural diversity, environmental justice, a constructivist pedagogy, and community involvement” (Marouli, 2002, p. 28). Marouli and many others have agreed that education needs to retain all pillars of sustainability in order to make waves with nontraditional educational models and to be a long term solution to the current learning environment in schools and after-school programs alike.

Garden-based education is one example of inclusive pedagogy. Thorp (2006) wrote extensively about a garden-based education program in a rural town in the midwest, with incredible insight as to why low-income, marginalized students deserve to grow food, learn about the natural environment, and gain vocational skills to use in other elements of life. The garden that Thorp started created a space for the students to grow 
food and build relationships with what and how we eat, while empowering the participants to obtain a unique connection with a specific space and time seasonally and emotionally. Thorp shared from her experience that, "the garden offered an alternative to the discontinuity and fragmentation of our modern culture. Questions of personal gain versus collective good seemed to slip away in our garden ecosystem” (Thorp, 2006, p. 33). The theory and practice of Thorp and many others exemplifies that the problems of education, "cannot be solved by the same kind of education that helped create the problems” (Fien, 2000, p. 9). For a student-centered movement, pedagogy needs, "the willingness and ability for students to practice civic responsibility” (Fien, 2000, p. 9). Power and privilege of food choices begin to become less entangled when young people are enabled to grow their own food and understand the vibrant relationship of where food comes from and their power to grow it for themselves and others. Farm-toschool programs have sprouted all over the country enabling the community to join forces in nutrition and healthy food-choices with education and hands-on, participatory learning (Fien, 2000; Marouli, 2002; Thorp, 2006; Tso \& Hill, 2006). This trend of participating in an active learning environment holds weight for the greater community by "Symboliz[ing] a new hope for small farms in urbanizing areas” (Vallianatos et al., 2004, p. 415). Farm-to-school programs have included student field trips to farms and farmers markets, school visits by farmers, and the development of school gardens where students can grow (and taste) their own food (Vallianatos et al., 2004).

It is important for students to have responsibility for the food they eat while promoting the relationship in serving the earth through food practices and sustainability. Farming and garden projects marry responsibility and relationships well as Waters and 
Duster (2006) have identified for the last 2 decades at the Edible School Yard in Berkeley, California. Providing a supportive space for educators, students, administrators and families is fundamental for garden-based projects to be successful. School garden programs are productive because they strive to highlight the multidisciplinary connections between gardening and many elements of the school or community environment; gardening is a model for educating the students and empowering them to grow their own produce while also engaging curricular and academic goals (Thorp, 2006).

Ozer (2007) detailed useful information as to why and how garden programs affect students and schools, as well as create healthy relationships and networks socially and environmentally. She outlined her research with micro- and macro-systems of life such as the site and activities, formal curriculum, and parent and community involvement; she then aligned the short-term and long-term effects of each element to the school garden program. Ozer discovered that having a garden on-site, exposes students to the produce, instigating positive attitudes toward eating fresh food. In addition to understanding where the food comes from and that fresh food is better than processed food from the store, the skills obtained in the garden aided in the prevention of obesity and chronic disease. Garden education pedagogy supports curricular goals and pride in the school setting, encourages on-site engagement amongst the school community, and enhances the extended knowledge that students share with their families in regards to nutrition, food systems and resource conservation. The benefits that come from a simple school garden are alarming and encouraging to those in the field, specifically those that are yearning for nontraditional models of education. 
The pedagogical anchors of garden-based education are that it is a multidisciplinary, multisensory, hands-on, and a sustainable avenue for engagement and participatory learning models (Parajuli, 2006; Williams, 2008). This is evident in most programs, and when garden-based education is threaded in after-school programs and alternative schools, young adults raise the bar as to the amount of work that can be done and how it extends throughout their community (Pothukuchi, 2004; Valliantos et al., 2004; Wekerle, 2004; Wynne, 2006).

Garden-based education also takes place beyond school environments, leading to an overall relationship that one gains from a garden and/or agricultural project; this practice includes developing environmental considerations, making cultural connections, pursuing humbling endeavors, and forming place-based identities. Vallianatos et al. (2004) would agree and allude to what Kaplan (1973) acknowledged that:

Hypothesized benefit (of "involuntary attention" that was claimed by William James (1892, derived from Kaplan, 1973, p. 146), centered on fascination, is clearly distinct from the more prosaic but still powerful benefit of harvesting one's own food, or participating in a basic survival process. (p. 146)

This psychological analysis of James dovetails the theory that Thorp (2006) paraphrased of Kahn, in saying:

The human relationship with nature is in fact a condition of both endogenous (innate wisdom or genetic) and exogenous (experientially stimulated) forces...suggesting that there is [a] need for transformative learning process that empower children [or any young adult or person] to construct their own values and truths about the natural environment. (p. 349)

Nontraditional ways of learning have not only empowered students in participation but have also engaged a new way of teaching and learning amongst and with the students, specifically in projects that involve marginalized groups that have often 
been left without one of the basic needs of human existence - food. In turn, gardens, programs, and inclusive school environments are places to learn, supporting learners and educators simultaneously.

After-school programs, as a nontraditional academic resource, strive to mediate relationships of authority to foster an academic and communal environment of success, for "respect, as a bidirectional trait, has been identified by youth as an important component of [students'] identities and experiences in after-school programs” (Deutsch \& Jones, 2008, p. 671). Kugler (2001) presented three concerns in modern day society that help to understand the evolution of after-school programs and why timing is pertinent to success. The three main outcomes addressed in Kugler's literature are: shifts in employment patterns in which young adults are left at home with no supervision, the creation of non-formal educational goals that improve academic success rates, and hosting a time for programming that runs from 3-8pm, a time when juvenile crime peaks. Kanter's (2001) research aligns with the work of Deutsch and Jones (2008) finding that after-school programming is a tool for success in the formal setting with overwhelming benefits in a nontraditional model of learning and engagement. After-school programs provide an environment and academic setting for students to learn and master specific skills in preparation for their futures, while being excited about learning. This is specifically vital in urban areas where there is a lack of resources in their schools and districts.

\section{Why Young Adults}

Youth are often frowned upon in their role in communities, especially given that most often than not they either want to "find a way out" with no pride in their sense of 
place or are completely removed and see no point in their role as change-makers

(Youniss \& Yates, 1997). Youth-led movements and programs that attempt to empower young adults need to face the reality that "regardless of ideology, any movement wishing to maintain long-term influence must recognize that young people represent the future” (Saunders, 2006, p. 1). The historical context of youth movements in this country is rooted in centuries of social and political action.

Neblett (1937) described how the overall boom and bust of World War II altered the outlook of youth, giving them actions and events to question and debate. At this time in history, what young adults saw and experienced during times of war and political strife began to empower them. Young people were beginning to stand up for themselves and those affected by the changes of culture and place that followed the war. The idea of a movement ebbed and flowed although it was rooted in possibility for all young people from then until the present day. The definition of a youth led movement is, "an organized effort on the part of youth itself directed toward a goal identified with the interests of young people and with the general welfare of society” (Neblett, 1937, p. 142). The evolution and development of youth is important to address, as well to distinguish the phases of personalities and awareness of certain issues pertaining to their charge for change. Attitude, as Fien (2000) put it, is a "complex concept, characterized by an embarrassing degree of ambiguity and confusion... with three structural dimensions: cognition, affect, and cognation” (p. 3), leading to one’s understanding of personal power and role in change. The change that Fien addressed is especially important for young adults who are dealing with developmental issues due to such factors as age and the questioning of their life course because development and education within this context 
needs to be carefully administered to empower young adults, mindful of one’s purpose and place.

Youniss and Yates (1997) have presented a strong argument for the strength and legitimacy of giving young adults the opportunities and to demonstrate their initiative to give their time in social service and responsibility and empowered to be "taken seriously as contributing members of society and to participate in meaningful, problem-solving actions” (p. 18). Being respected and taken seriously requires a paradigm shift of authority and education through progressive models of pedagogy and authority.

There are many hardships in escaping poverty: for example, a generational victim mentality forms because young people are without the resources of social capital and networks and "the quality of social relationships in generating norms of reciprocity, mutuality and trust” (Fahmy, 2006, p. 115). Before young adults are pigeonholed in an unsuccessful track and become "driven further towards the social margins” (Pitts, 2002, p. 9), rebuilding social capital and self-confidence from theories of empowerment and revitalization is critical (Fahmy, 2006; Pitts, 2002; Serow, 1989).

Specific program modalities have the potential to work with young adults and set them up for success. Youniss and Yates (1997, pp. 135-153) concluded their research on community service and social responsibility in youth by outlining 10 ideas for implementing and designing community-service programs, including an emphasis on: (a) Meaningful activities, (b) Emphasis on helping others, (c) Integrated part of articulated ideology, (d) Group rather than individual action, (e) Reflective opportunities with peers, (f) Service organizers as models and integrators, (g) Site supervisors as models, (h) Acknowledging participants’ diversity, (i) Sense of being a part of history, (j) 
Responsibility. The ideas that they have outlined are targeted to an audience of educators and program professionals as a helpful resource to utilize in current and future programming. Each suggested idea accounts for their specific research at a local high school.

Young adolescents are dynamic beings with multiple developmental influences and life events that drive decisions and their course of life (Youniss \& Yates, 1997). Reaching beyond the self and becoming a part of history, while caring and maintaining responsible citizenry and significant relationships, are vital for a successful project and milieu.

Programs across the United States have been started to eradicate poverty while assessing a community's basic needs. However, it is important to gain perspectives from young adults regarding change and their local community through leadership and organizing. Success emerges when "education campaigns [are] directed at youth to demystify the global and corporate domination of food systems” (Wekerle, 2004, p. 381). The future and welfare of the environmental, social, and economic structures of society are in the hands of young people. It is imperative that they are empowered and inspired to be stewards and change makers while also provided a learning environment that considers their strengths and encourages their leadership and willingness to wrestle with cutting-edge, real life issues and place-based movements.

\section{Paradigm Shift}

In offering a paradigm shift from social, environmental, and economic entitlement, which is currently shaping a privileged audience's perspective of environmental and social stewardship, it is important to determine society's current 
stance, the potential and focus for change, and the vision come to fruition of meeting the basic needs of all people. The potential for change is at the forefront of society, and it is everyone's onus to make it happen, specifically the young adults that hold the power for future community building, food security and personal leadership development.

Literature presents multiple perspectives that make sense of the vast, critical theory of sustainable, community oriented projects. It is fundamental to explore literature in order to frame the broad ideas offered, and consequently, to widen the lens of how theory can be put into practice.

The new sense of possibility, which Berry (1972) has clearly elicited in his literature and poetry in response to environmental and social issues is the foundation of change and future sustainability. He has noted that many of the possibilities are within an overall shift of power. It is up to individuals to retain their personal power and courage, for "free men are not set free by their government: they have set their government free of themselves; they have made it unnecessary” (p. 123). The shift is embedded in an overall change in consciousness, and the marginalized, working class, or non-working class has to adopt this frame of thinking to move forward (Alinsky, 1971), because the government is not leading the fight. History and present day findings make this very clear. Adopting the paradigm shift suggested by both Orr (2002) and Berry (2009) is what cradles change and democratic livelihood in social and environmental awareness.

Corporate food conglomerates encourage people and communities to be pawns who are then swept through the system with few options for choices that the larger system of capitalism and cooperate dominance do not deliver. Orr (2002) has pointed out that when a system is moving at a rapid pace, there is a large population who remain 
behind with polarized economies and inequitable resources. Food policies are embedded in equality and resource accessibility. The pace of the system that Orr described and the class-based access are why the ghettos and underserved populations are left without basic needs and why communities fall apart with no conception of an alternate perspective (Jones, 2008). In order for people to breach out of societal-ran, pigeon-holed development, those that are currently neglected and mistreated have to take their power and initiate change, while, "respecting[ing] and learn[ing] to live with other political ideologies," for change has to occur with "friction” (Alinksy, 1971, p. 21).

In considering a paradigm shift from industrial-led communities to a union of people living with the natural world and celebrating the similarities and differences, Berry (1972) stated that, "we [need to] realize that we do not live on the earth, but with and within its life” (p. 10). People will accomplish living within the life of the earth when they learn to restructure their relationships and ideals involving success and accomplishment, particularly in regards to social and environmental development amongst the current societal structure. Such restructuring needs to be "equipped to comprehend such things [as change]" (Orr, 2002, p. 73), as "preserving ecological capital” (Orr, 2002, p. 49).

Shiva (2005) announced the term Earth Democracy, as a model with multiple principles that consider the balance between the human and non-human world, understanding that communities and the earth have the potential to weave within one another. Shiva stated that Earth Democracy is "both an ancient worldview and an emergent political movement for peace, justice, and sustainability...connect [ing] the particular to the universal, the diverse to the common, and the local to the global” (p. 1). 
It is understood from Shiva's work how conceptualizing the interconnectedness and diversity of all living things will ultimately provide perspective and understanding of place and time, as well as respect life beyond human beings; this is the shift in paradigms that propels forward thinking ideology.

There are numerous approaches in qualitative research that parallel the ideas that Orr (2002), Berry (1972), and Shiva (2005) delivered in their literature. Guba and Lincoln (1994) critiqued the nature of paradigms as basic beliefs that fall under the ontological, epistemological, and methodological questions of logical primacy (p. 108). Humans construct ideas and paradigms from an individual perspective and because of this, analysis must be grounded and understood from the individual's own ways of knowing while simultaneously understanding the causes and effects of stewardship and interconnectedness with the natural environment and their communities.

Berry (as cited in Bonzo \& Stevens, 2008) stated that, "a community is like an ecosystem, and it includes - or it makes itself harmoniously part of-its local ecosystem” (p. 14). For people to ingrain themselves in their local ecosystem toward change, they have to believe in their power to change their place and personal power in the system; furthermore, they must find a common ground to build upon the medium of justice and adapting to personal power ideologies (Smock, 2004). In sustainability, the discourse needs to be focused on a broader audience regarding both urban and ecological issues (Jones, 2008). Education for sustainable development empowers this framework by including social, environmental, and economic strategies (McKeown, 2002) for revitalization of the commons and justice for all living things although McKeown's model is weighted in class-based democracy. Sterling (2001) noted in Sustainable 
Education that the re-directing of sustainability is a social and evolutionary process that happens consciously at:

...individual and social levels...[initiating] a deep learning which questions and examines our basic assumptions and values and intentionally speeds the mergence of the core values of sustainability such as sufficiency, efficiency, community, locality, health, democracy, equity, justice and diversity. (p. 16)

Jones (2008), as a leader in inclusive environmental action, marks clear examples and alternatives for retracting the reliance that society has on corporate markets. He discusses the vitality of diversifying the democratic and ecological paradigm all together. Shiva (2005) also presented the overwhelming need of diversity. Although without the critique of past movements that Jones presented, she focused more on the present day issues and the pertinent evolution from the capital market to a new sense of the commons with transparency and cultural inclusion. Jones’ critique argued that the environmental movement, historically, has been powered by a white, upper-class population, which places priority on broader concepts of environmental mediation, such as endangered species; meanwhile, they neglect the basic needs of communities and people. The manipulation of the natural world is also happening to people and communities. Overall, society is intimidated to reform because it would require people to face the real issues of elitist environmentalism that are affecting everyone all over the world. Who are the endangered species? According to Jones the communities that are socially degraded are also endangered. Jones stated:

Let's rehabilitate the South Bronx, and all the other places like it across the Earth. To accomplish that, we must give the unemployed and the never employed a stake in the wider restoration process. Let's also put environmental conscience into world race and into our corporate thinking. (p. 42) 
Jones (2008) asserted that in order to understand the issues that are simultaneously affecting the planet and those living on it, there is a need for inclusion of different ages, classes, ethnicities (and most everyone that has been excluded since the environmental revolution of Rachel Carson and others that pioneered the movement decades ago). Jones (2008, p. 9) called for the Green Collar Economy and the paradigm shift of equality both for the Earth and those that live on it.

It is difficult to find a political platform of inclusive social and environmental discourse regarding food policy. Wekerle (2004) suggested that for alternative theory to become part of public practice, de-linking strategies and critical conceptualization of food and community security need to be adopted that will initiate an overall paradigm shift from global based markets to local place-based community efforts. For instance:

Growing food in the city, developing a regional food system, buy-local campaigns, or microenterprises may be seen as de-linking strategies, small initiates that de-link local economies form the corporate controlled global food system. (Wekerle, 2006, p. 381)

De-linking strategies are at the heart of the food justice movement, and this review of literature suggests that these are the nucleus of the overall paradigm shift. These strategies are critical in incorporating a diverse audience and presenting a choice of freedom to those that have been absent and undeniably removed from the discourse. As Appadurai wrote in Wekerle’s (2004) research, “challenging existing forms of governmentality as poor people engage in developing their own knowledge base and solutions to better the lives of the poor” (p. 380), is essential to honor equitable change for all people. 
A paradigm shift toward sustainability and youth empowerment involves diversity in relation to age, class, gender, ethnicity, worldview and experience. The shift needs to be embedded in how education is structured and how food systems are understood. The shift of power, privilege and access to food policy and theory is one promising avenue to revitalize communities and seek an alternative to development, all while retaining a relationship with the land. Research that investigates the power and commitment of youth, specifically their inherent role as change-makers and intellectuals of rigorous and just discourse, is essential in moving forward and bridging the gap between environmental awareness, community development, and food access. 


\section{CHAPTER III}

\section{RESEARCH METHODOLOGY}

The central focus of this qualitative study is to understand why, and in what ways, young adults are appropriate agents for community revitalizing garden-based projects.

For this, two youth development and community service oriented projects, one in Olympia, Washington, and one in Ashland, Oregon, serve as sites for the study. Algozzine and Hancock (2006) confirmed that "Ethnographic studies...investigate intact cultural or social groups to find and describe beliefs, values, and attitudes that structure the behavior, language, and interactions of the group” (p. 9). My research interest is to gain perspective of two different organizations with a common thread of young adults involved in garden projects that enhance their social and environmental stewardship. I accommodate garden and farming under the same umbrella since I am interested in young adults’ involvement with food and community.

Garden Rasied Bounty (GRuB) is a state-of-the-art after-school program that promotes social justice via food security while initiating success in academics, environmental stewardship, and activism. GRuB, previously Holly Sister Garden, is a nonprofit organization in Olympia, Washington, that was founded in 1996 by Blue Peetz and Kim Gaffi. Both harnessed a vision to grow food with young adults and share their passion for group development and environmental stewardship with low-income participants from nearby high schools. GRuB’s mission is stated as: “Good food for all 
people.” Bonnie Turner initially owned the land and with her trust in the vision and mission of GRuB, she agreed to open her wood-nestled, small tributary of open space that was her backyard to the GRuB organization in order to start a youth garden project. Bonnie Turner eventually passed, and with her, the livelihood of growing food and gardening for over 60 years; her family sold the 3-acre parcel to GRuB to continue her legacy by maintaining the space for gardening. As presented in GRuB's mission statement and profile of goals and stewardship, "rigorous curriculum is designed to build and increase self-esteem, leadership, academic success and self-care skills, and to improve nutrition” (Garden Raised Bounty Website, 2010, para 1).

The Medford Opportunity High School (MOHS) is an alterative high school in Medford, Oregon hosting 200 students in a nontraditional educational setting. The nontraditional charter-school is located in the heart of Medford with roughly 30 teachers serving a diverse student population from the Medford area. A unique program, the Medford Youth Cooperative, in association with Medford's Job Council, is a school program nestled within the school, which takes low-income students into the natural environment to work on the vocational skills-based tasks of gardening, environmental stewardship and other community related projects that encourage students to leave campus and participate in service learning projects. Kate Giles piloted the Job Council program in 2007. The program currently assists the Medford Youth Cooperative at MOHS. Molly McLaughlin was invited into the program in 2009, to assist in the programming and classes, in conjunction with the Medford Job Council. Both instructors believe in and strive for a safe place for MOHS students to work hard, play hard, and learn about the natural world that is often distant from their daily lives in Medford. The 
strength of one’s voice is central to community empowerment and one’s ability to influence direction of change. This is a key purpose of both programs.

The young adults in both programs possess the perspective to articulate precisely why they are participants, what their role is in their communities, how their personal power has evolved in the process, and how this reflects their role in society as lowincome, underserved young adults.

To further my research and conceptualization of the subject and its challenges I broaden my understanding of young adults and their development and perspectives. The goal of instrumental case studies is to, "better understand a theoretical question or problem... understanding of the particular issue being examined is of secondary importance to a greater insight of the theoretical explanation that underpins the issue” (Algozzine \& Hancock, 2006, p. 32). By studying garden-based, non-formal education, multicultural education, after-school programming and by drawing from community development theory to ground my research, there is potential to identifying how these concepts are integral to an overall paradigm shift from socio-economic power and privilege to justice and sustainability across the human and non-human world (Jones, 2008; Shiva, 2005; Winne, 2008). I am not directly connected with the programs and have spent a limited amount of time with each program, with restricted workdays and interviews due to program planning and seasonal variation. However, I am also an insider and someone who "understands the situation under investigation primarily from the participants” (Algozzine \& Hancock, 2006, p. 8) because I possess years of experience working with young adults from diverse socio-economic backgrounds, as well as years of teaching in a garden-based setting with similar goals that are fundamental to each 
program. It is a unique position: “detachment and involvement, subjectivity and objectivity, insider and outsider stances are equally coupled in field working” (ChiseriStrater \& Sunstein, 2006, p. 9). A passage from my December $12^{\text {th }}$ field notes affirms this:

I walk into the GRuB headquarters, and it is evident that the staff and participants know I am coming. I am nervous and excited about what I am going to learn from everyone. I am an outsider in this organization, but they welcome me and ask questions immediately - with great honesty - about who I am, why I am here, and the point in me interviewing. After time has passed, I feel less out of place. I am sharing my experiences with the participants about gardening and music, giving insight about PSU to staff and exchanging recipes with the guest chef of the day. My personality and prior experiences have bridged the insider/outsider role of a researcher; I am trusted, and they have shared that with me. After lunch I will work in the field and will be given a tour of the place...wow! This place is state of the art, and I want to take it all in.

December $13^{\text {th }}$ field notes:

After a day, it appears that I am somewhat part of their community. I was driving to the site, and a young boy who gave me a tour the day before ran by my car, waving on his way to the bus with a smile that indicated I was welcomed. Often times young adults are intimidating; however, with my offered respect and inquiry into their opinions, I defeated the barriers.

\section{Subject Recruitment}

Every day, young adults are negotiating stereotypes and grappling with what their role in society is and how they can fulfill this. Because of the power and potential that young adults foster, I am particularly interested in their perspective on the issue of garden-based projects involving their age group. I chose to research high school students because they are the future, and when given the platform to serve others and learn about themselves and their personal power, they thrive and succeed in their personal and professional lives (Youniss \& Yates, 1997). The purpose of understanding young adults and their perspective is to determine how to create programs and design sustainable 
models for future programming that young adults will take seriously - while also considering what components in food-based projects are tangible and relative to their livelihood. My passion for being in the outdoors and striving to learn more about gardening and agricultural projects has grown because of the young adults that I have worked with in the past. I knew that this age group would be best to question and learn from given the perspective I had gained from them and the trust I had developed with them. It was now time to empower their voice and perspective in research.

The GRuB program in Olympia, and the Medford Youth Cooperative (MYC) in Southern Oregon are similar in that they serve low-income, at-risk students as a vocational training and life-skills component of education and after-school programming. Each serves the same age group and demographic that is integral to the research, and both programs center around gardening/agricultural goals. There are roughly 20 students in each program, with a focus on growing food and learning about social and environmental issues that are associated with feeding themselves, providing local food for soup kitchens, and tending the land. This research ultimately seeks to document young adults' experiences, perspectives and visions in order to frame and develop a programming model with explicit, sustainable characteristics, which will be usable in multiple urban and rural spaces and will empower young people as leaders for change, especially those that are initially from impoverished areas.

To gain the perspective and knowledge of each participant, I chose to interview 11 participants from both programs. There were four males, seven females. Five of the participants were white, four were Latinos, and two were African-American. I implemented triangulation methodologies by studying secondary information about each 
program on-line and from each organization during site visits. I also conducted semistructured/narrative interviews, collected field notes and observations, and analyzed photos that I took when visiting the sites and throughout my interactions with participants. Furthermore, throughout this process I engaged in multiple phases of coding the data that maintained reliability in the topics and emerging themes. Each component of methodology was unique and served its purpose of rigorous research and critical examination of the information.

Narrative, story-based literature enables me to see beyond an academic and institutionalized component of research and delivery (Klindienst, 2006). Examples of literature and research that embody these qualities are intriguing and provide a foundation for nontraditional research methodology. Personal stories have an organic flow and are pleasant to the reader, and this is important for my delivery and style of research (Klindienst, 2006; Thorp, 2006).

\section{Semi-Structured, Narrative-Based Interviews}

Given that my research is unannounced with specific outcomes, open-ended interviews (see Appendix A) with narrative-based dialogue are exceptional ways to gain insight into the personality and perspective of the participants without having ample time to observe and familiarize myself with all of particulars of the organization. Narrativebased observations and interviews were also important tools for the participants to share why they do or do not believe in the program and how it influences other realms of their lives. While I conducted the interviews, I posed follow up questions that were in an openended format with deliberate inquiry, consistently asking if there were specific stories that were associated with an answer or if there was anything else participants wanted to 
share. This made the interviews more conversational and enabled exceptional thoroughness in this research because when stories are collected, they are not necessarily formalized; they are "interpretations of a storied life” (Savin-Baden \& Van Niekerk, 2007, p. 464). Ultimately, narrative inquiry allowed me to "learn from the people, versus having a superior theoretical attitude of studying about them” (Hale et al., 2008, p. 1418).

In addition, the semi-structured component permitted me to "invite interviewees to express themselves openly and freely and to define the world from their own perspectives” (Algozzine \& Hancock, 2006, p. 40). Specifically with young adults, it is important to empower them to tell a story and go deeper because "we may be able to learn how to recover our sense of identification with the earth by listening to stories from other cultures... perceptions of universal wholeness and the identification of human existence” (Gough, 1990, p. 15); consequently, we can understand the multidimensional perspectives of being a young adult serving a community and working in a nontraditional setting. I was sure that gardening and/or farming would be an added bonus and I was intrigued to learn more about their experiences and what existed below the surface. I wanted to delve deeper into the participants' experience, and this methodology served the research well.

\section{Field Notes and Observations}

As an outsider I was stimulated immediately, and my notes proved to be an integral piece of my research. I was amazed at the culture and foundation of each

program, how different yet similar they were, and the thoughtful ideas that I gathered and acquired working and interviewing participants. I knew that the interviews, once transcribed, would be critical for what I was seeking in regards to findings and 
conclusions in my research. The extensive field notes I gathered provided a platform for my personal story, a place from which I thread and spin a thoughtful perspective into the research.

While spending time with each program and the sample of participants, I was becoming part of the research: learning the model of the program and getting to know the research participants as people beyond interviews and the quiet room that I was recording them in. My notes verified this: when I reviewed my notes, I found that the bulk of my information gathered was a tapestry of little stories providing evidence as to what and why the participants were in the specific program. When I reread my reflections, with so many events transpiring and ample amounts of inspiration, I was able to draw conclusions that were previously unattainable.

\section{Photos}

My love for photography has stemmed from my travels. I learned, through traveling, that I am able to capture something for the first time, knowing it could be my last, and always have a token of it in an image. Because of my passion for images, I document my life with photographs. Therefore, it seemed appropriate to include photography in my research process, similar to the role of my notes and observations. Due to human subject guidelines, the photos remained in my possession and were erased after a review of the visits to ensure the safety and protection of my participants. They served as wonderful resources for analyzing relationships and events from my visits, as well as enabled me to have another medium to analyze and configure the research samples in order to "move past the obvious themes of their images and engage in richer inference-making processes” (Zenkov \& Harmon, 2009, p. 578). 


\section{Coding}

I transcribed each interview, followed by a coding process of categorizing the information into major themes that were consistent in the responses. I then separated each response in a designated theme or sub-topic. After compiling some 50 or so pages, I was able to re-code the information and cross reference it with my field notes and photos to then narrow down the concepts once again, leaving me with only the most important topics and responses to reconfigure in the same sub-topics that I had chosen originally. The process of coding enabled me to stay grounded with consistent sub-topics and themes, while narrowing down big ideas and categorizing interview responses to make sense of the enormous amounts of information I had gathered.

\section{Secondary Sources}

The internet evolved as an additional helpful resource for collecting information about the programs, their mission statements, recruitment, and projects from an objective perspective. Due to the distance between where I live and the location of the programs, the internet served as a tool of research to learn about the organizations and last minute logistics before going into interviews, which then enabled me to ask relevant questions pertaining to local projects and partners. With the new age phenomenon of blogs, many organizations solicit their programs and provide updates so that one can learn more about what is being done on the ground and how projects are working. Again, it was a space for me to learn about the program through narratives, photos, and a subjective delivery. However, although it assisted in checking ideas and solidifying conclusions, in no way would I rely on this as a sole or objective resource. 
Moreover, I am fortunate to be surrounded by many garden-based educators, professors and students to cross-reference and debrief ideas and concepts that had come up for me throughout the process. Once I had collected my data, I found coding my information and identifying sub-topics was helpful in grounding my research and conclusions. With multiple sources and many thoughtful responses from interviewees, compiling and organizing data was important to assure that larger concepts and ideas were consistent in the findings.

Also, I made sure to capture each participant's voice in each sub-topic that was coded, not only to ensure reliability in the research but to achieve my goal of student-led discourse and delivery. For every step in the process of this research, I tried to cross check my notes to ensure consistency of information.

\section{My Role as a Researcher}

My experience as a garden educator coupled with an undisputed passion for working with young adults most of my adult career enabled me to build relationships easily without the intimidation and fright that most people have when working and interacting with this age group and/or demographic. I developed a rapport among the participants in both programs once I shared why I was particularly interested in their input and explained the necessity for after-school and in-school programming to be available for current and future students locally, nationally and globally. Multiple questions arose from everyone about what I was doing and why. After a short period of discussion, small talk, and introductions, stories surfaced; people from all parties felt comfortable and engaged, and the work and research began. 


\section{CHAPTER IV}

\section{RESULTS AND ANALYSIS}

Research analysis was a complex process, and the more that I tried to consolidate the data together in just the right way, the more I found myself digging for meaning since I wanted to ensure that I had captured my participants' voices accurately. Furthermore, I was fascinated by each site I visited and every discussion and workshop I witnessed. Each participant that I met was vastly knowledgeable in what I was searching for in this research. Witnessing the interactions and the tasks that make up the daily routine of both programs provided clear evidence of the rigorous programming. I remember very clearly coming home from Olympia on a cold winter morning and replaying the site tour over and over as I listened to two participants sharing stories and site specifics. Big ideas and models became apparent at the GRuB site, and knowing that I was given the time and space to ask questions and learn from the young adult participants seemed quite unbelievable at times.

I was genuinely enthralled by what each person had to say - not only the students. My interactions and familiarity with the staff as fellow garden educators and facilitators made it easy to be specific and build off of something that was familiar to all of us. I was comfortable at each site in order to establish a foundation to work and identify with, my analysis from the start included the interactions and energy of this dynamic group. I appreciated the way the classrooms and open shared spaces flourished with stories, 
photos, and insights into the world of young adults working outside. The atmosphere was anchoring, and my perceptions evolved in discerning what happens at each site on a daily basis. Given that I was unable to visit more than a handful of times, anything that I could gather was vital material for my research.

Both programs under investigation are unique and engage participants because of the specific models that each program practices. In the GRuB program specifically, 20 students from nearby high schools are hired as farmers and land stewards to learn about agricultural principles, business skills, and social issues for the entire summer, along with leadership opportunities that continue into the school year. The three themes of the organization are: farm the self, farm the community, and farm the land. The program supplements science education with the option for participants to obtain .5 credits for high school completion, as well as avenues for employment and obtaining life-skills while also providing opportunities to take fresh food to the families and participants in the program.

Farming the self ensures that the participants receive support in academic planning, one on one goal setting with staff, communication and leadership skills, and participation in workshops that engage topics from gender awareness and social equity to nutrition and food security. Most of the participants enter the program with little selfconfidence and social capital, and when given the opportunity for communication, leniency of expression, and personal power, they are encouraged to speak out about the issues of food and equity while also promoting their mission to provide good food for all people. 
Farming the community encourages the participants to share with the community about the hard work and elements of service being done at GRuB. Participants engage with the community by leading volunteers, speaking at city council roundtables, and educating local businesses and agencies, as well as the general public, about the work they do. The community engagement's goal is to involve multiple people from diverse perspectives and audiences and help them to recognize how important their work is for the future of food and community cohesiveness, sustainability and equity.

Farming the land includes selling and marketing community supported agriculture shares, growing flowers for arrangements to sell to 30 businesses and offices in the area, donating large portions of their harvest to the Thurston County Food Bank, all while feeding themselves and their families along the way.

Once the annual harvest has passed, the program continues with less emphasis on farming and gardening tasks and more on seasonal clean-up, community building, and training for previous years' participants to graduate to Peer Crew Leaders (PCL). PCLs and on-site staff teach the next phase of youth crewmembers.

The Job Council program runs throughout the school year and breaks during the summer months. This program is a unique class amongst the other scheduled core classes and provides the students an opportunity to utilize their skills from the classroom in an outdoor setting. Most of the students in the program participate for two to three years. The admittance process itself exemplifies the student-led milieu of the program because it requires that prospective students are interviewed by their peers and instructors, which also reflects the process they would experience with a future prospective employer. 
The Medford Job Council, a non-profit located in the Rogue valley, funds the program and strives to create partnerships that are socially and environmentally fitting to the needs of the community. The focal mission of the MYC is to ensure that nontraditional students in the MOHS are able to engage in a hands-on, outdoor learning experience. There are 20 students in the program. Each student spends roughly eight hours a week working on service learning projects in the communities of Ashland and Medford while earning credits and connecting with the natural environment. Students engage in various main tasks and educational service projects, including educational service projects are garden-based learning and inquiry of growing food, cooking food, and serving food at a local soup kitchen in Ashland, creating community garden plots and raised beds in community gardens in Ashland and Medford, and any other garden implementation that may be needed in the valley, including the local University in Ashland, Southern Oregon University. When the participants of the MYC are not in a local garden, they are working on habitat rehabilitation and removing blackberries, along with multiple other invasive species that are detrimental to the native environment.

I was beginning to learn about the programs and discover my edge as a researcher. I began to investigate the fundamentals of the program along with the specific models that have been adopted. As LeCompte and Schensul (1999) claimed in their toolkit of research and design, "ethnographers need to engage in several levels of analysis as they go along...the overall picture never becomes clear all at once, instead it slowly emerges from a morass of observations, interviews, and other kinds of information” (p. 149). The succession and the process of understanding all that I was exposed to was an accumulation of information, like a patchwork of ideas and concepts to sew together for 
clear and concise analysis. As I deliver my research and findings, I will do my best to take the reader through the process that I was fortunate to undergo.

\section{Findings and Themes}

I asked a series of open-ended questions. I also took photographs and field notes of my observations. I used secondary sources, such as the internet and educational pamphlets/resources for methodology and assurance of triangulation and reputable sourcing. Open-ended interviews weigh heavy in emotion and rigor, specifically when working with valuable young adults that bear wisdom and grace in all they deliver. Personal perspectives and life stories unfold for thorough research and content when young adults are finally asked their opinion and invited and empowered to engage in big ideas (Pitts, 2002; Saunders, 2006; Youniss \& Yates, 1997).

Similar to most ethnographic researchers, I had assumptions about my sample related to cultural identity, place-based learning, and youth development and engagement. Theoretical framing and synthesis associated with young adults and their development include major issues and topics that have been adopted by both programs.

I compiled 25 interview questions (as seen in Appendix A), which inform my research. These cover a broad range of topics, such as youth perspectives and interpretation of community interactions, food security and growing food, environmental awareness, programming modalities, and other specifics that were dependent on the responses and input from individual participants. Each interview started with a series of questions about each participant's role in their specific program, length of involvement involved, length of residency in the specific area, and reason they believed it was important that young adults be given the responsibility and opportunity to work and learn 
in environments like GRuB and the MOHS Job Council. Also, to protect the identity of the participants and to illustrate the similar context in which the students engaged in the topics explored, I have combined the quotes with responses from both programs.

Both organizations were consistent in their ultimate goal: to serve young adults and prepare them to be leaders in social and environmental stewardship while being outside in the natural environment amongst the elements. The milieu that each program established is unique in that both are totally student led. Participants are engaged through forms of empowerment and tangible content that are relative to their lives. Because GRuB is an older program of 10 years running in an after-school setting, certain modalities were very different than those at Job Council. Overall, both programs allowed the voices of the participants to flourish in discussions and hands-on work time. After reading research about how important it is to give young adults power in change-making projects (Berry, 1987; Deutsch \& Jones, 2008; Fien, 2000; Youniss \& Yates, 1997), it was both validating and refreshing to see the two organizations actively apply this practice. Each program is excellent at facilitation and group management in a studentcentered environment.

Given that this project focuses on youth perspectives, most of the questions in the interviews associated big ideas as a foundation for youth involvement and the role that young adults play in regards to social, environmental and economic issues. Each participant had many ideas as to why their role is vital in the process of stewardship and action. Most participants shared that it is important that they are involved in their individual program because they represent the future, and it is their role as young adults to teach the next generation and set a standard for change. Participants are inclined to 
change the current system and use their age and ample time as a motivator for action. My interviews included both students who have been involved in the program for more than a year and those who were recent participants in the last three to six months.

I believe that it is important to hear from young adults and understand their perspectives on youth and future leadership. The participants' voices set the stage for the findings and results that have emerged in this research, conveying a sense of why young adults should be at the forefront of community action and sustainable practices. The quotes below provide a foundation that helps establish the reader's conceptualization of not only the young adults' contexts but their dedication as leaders, learners, community members, and advocates.

\section{Commitment to Service and Action as Young Adults}

The eagerness to serve as the next generation in the movement for justice and equality yields from commitment and dedication to service. Once the participants engage in the ideas of food security and service, coupled with the content of real world ideas and perspectives, the commitment to action is heartfelt and a part of their being.

When we put all of our energy into this and it helps us realize that we can be dedicated to anything that we want to do, anything that we really, really want to do. If you get kids together doing something for the community, when they are teenagers it helps them grow and expand on that when they are older and go out into the community. I think, if we learn how to grow food now, and learn how to eat healthy now, we will eat healthier later in life and teach that to our kids. I just think that getting youth together to reach a goal, and our goal is good food for all people, I just think that youth is where it starts and if we can get youth and food together then pretty much, I think it is peace! - Aaron

We have so much to offer, we are young, we are at our peak, maybe not emotionally or mentally, but physically we are able to do all of this stuff. Teenagers have a lot to offer, whether they think so or not. We want to take advantage of the ability to help, that is why it is important, and it benefits 
teenagers, to boost their confidence and self-esteem to know they are doing something and that people can view them and notice they are doing something. - Alison

The aforementioned quotes evidence the importance in providing a space for young adults to work together while also raising the bar for academic and social excellence with regard to goal setting and taking advantage of the youth's traits of time and energy.

\section{Alleviate Stereotypes of Young Adults as Lazy Citizens}

Stereotypes and assumptions from society have also hindered people in taking young adults seriously and trusting that youth are committed to excellence and service. There is a sense of pride that emerged from the interviews relating to proving society wrong and providing evidence for their hard work and dedication.

Some of the adults, they kind of assume that teenagers are rowdy and trouble makers and always in jail, and yeah, that happens, but not all of us. I think we can prove them wrong with this organization and we have proved them wrong, those that are supportive here. - Olanda

We are young, we are motivated to do something to make us happy to make us feel like we are important, because the community doesn't think so - a lot of people in the community don't think so, we are teenagers, but it is important to other people and ourselves to do these things. - Alison

\section{Youth Perspectives on Youth as our Future}

The role that young adults harness in being the next generation is portrayed as a form of commitment and obligation. The participants' responses encourage their audience to respect and acknowledge that they understand the necessity for their generation to serve others and take responsibility in social and environmental issues.

So that we can keep it [sustainable practices and stewardship] going. And know how to do it [work and serve others], and teach the next generation. I see myself teaching in the future. - Jessica 
They [young adults] are the future and they are the ones that are going to college and the next jobs right after the [current] generation that is there, and they are setting up what is going to be held in our government or in our schools and everything else. It really depends on their view and how they are going to shape the world. - Synthia

We are the future. Everything that we learn now is what we will be teaching our kids, especially if they teach us to get involved and love what this is, then we will value work and projects later. You feel better about yourself and you want to do more for your community. If teenagers are willing to give up their social life to help our community, why can't we do it [in response to young adults being leaders to older generations]. - Justina

So that our generation doesn't just mess it all up. The generation before ours was getting down on the gardening and local food and now everything is coming from other places and nobody does anything. - Ranaldo

Somebody has to keep it going. I would say because they [young adults] don't have a good sense of community: An interaction between the younger adults and the older adults [is important]. - Matt

Because they are the future. Young people can make a huge change when they come together. Cheryl

Educational and pedagogical themes emerged and evolved amongst the camaraderie of the youth’s energy and the adults' willingness to retract from stereotypes and assumptions. Inter-generational learning and community development are another set of themes consistently appeared in the interviews, as well as the exploration of youth as future leaders and models of sustainability and continuity. Selfless identity and the willingness to serve are also valuable to note as worthy traits of young adults and their personal leadership.

Each young adult's response clearly indicates the desire for responsibility and accountability in the act of change. The overarching conclusion from my experiences at both sites is that young people want to be the engines in this movement, and they 
recognize that they have a lot to learn and have no problem undertaking the challenge. When I visited the Job Council site in Medford, I witnessed a group discussion identifying perspectives of food security and access. The students were motivated and willing to learn. One young man left the discussion stating how much he loved "this stuff.” It was evident that he and many of his peers felt fortunate and excited to discuss these ideas and topics; even though this content was not normalized in this young man's everyday culture, he recognized its value. Consequently, his behavior cast an overwhelming sense of responsibility.

Time and time again, participants from both programs related the ideas of food security and assisting others with their youthful energy and the ample time they possess as young adults. The let's get `em mentality resonated in everything the participants said and discussed, as well as in the ways they acted and motivated themselves as a group. My field notes perpetually state how descriptive everyone was when engaged in topics of food and security - this was evident at both sites equally.

After my initial questions of getting to know each participant, it was easier to gain a sense of what individual participants value in the outlined topics, providing insight to the following open-ended portion of the interview. I weighted the subsequent questions pertaining to community development, food security, leadership development, sustainability, program modalities, and power and privilege. From the questions I posed, multiple ideas evolved, corresponding to the theoretical findings of literature I researched. In turn, the theories explored began to match the responses and characteristics of the participants, providing space and time to truly capture what the participants valued in the programs, especially with regards to youth involvement. 
From the start I was ascertaining patterns that included major themes associated with the social components of food security and the feelings of accomplishment that were attached to participants' experiences feeding the homeless and interacting with an often forgotten, stigmatized population. Social transformation and accomplishment emerged as important traits that complimented and inspired further discussion and inquiry into clear and specific topics. A gentle evolution proceeded from my first to last interview. Given that every participant from my sample size lives below the poverty line, I became more and more interested in their relationship with feeding a homeless population as lowincome, young people. I started to wonder, what was this experience evoking in them, and how did this influence their personal power as young people helping others? The thought of low-income students feeding low-income residents in their area was not initially a component of my research, yet it evolved into noteworthy practical evidence for grounding the study's findings. The beauty of open-ended inquiry unfolded in every interview, and I was able to use my people skills and explore certain questions according to what themes were evident in the responses from each participant in order to gain a deeper perspective of why, how, and in what specific ways young adults are vital in community oriented garden-based projects.

All participants gave confident, well-versed answers and provided evidence as to the significance of their role in either program. The overall sense I gathered was that the participants undoubtedly believe that they are the future and that the nontraditional model of growing food as young adults and serving a purpose in providing basic needs to others is important, if not essential. Along with weaving skills of social awareness and 
sensitivity that bind each program to the bigger picture of environmental and social stewardship, the students engaged in and were aware of the importance of aiding others.

The findings developed specifics that seemed to arise perpetually in every interaction and interview that I conducted. These included: an overwhelming critique of traditional programming, importance of nontraditional education models and pedagogy, the necessity of young adults as leaders in community development and food security projects, the evolution of leadership development and life skills, personal power and transformation in youth-led projects, and a conceptual understanding of environmental and social stewardship. I decided to split up the literature and findings into sections of specific topics that are continuous throughout the research in order to share what seemed most appropriate from the voices of the young adults that I interviewed. From 11 interviews administered and hours of observation, I obtained real-life information and responses from the participants and their experiences as young, motivated, environmental and social activists.

For the purpose and integrity of this research, and in order to remain true and empathetic to the foundation of what I seek to convey in this project, I want to further highlight and present as many of the voices of my participants as possible. I will try to incorporate key facts and figures that support their words. As Freire (1970) said, "The revolutionary's role is to liberate, and be liberated, with the people-not to win them over" (p. 84). I believe that in order to remain grounded in my purpose and execution of hearing from young adults in regards to garden-based community projects, this portion of my research needs to be a dance of shared interest and analysis - between myself as the researcher, and the participants as the chief voice of the study. This is the showcase and 
testimony of what underserved, talented, young adults affirm concerning their experience and leadership in social and environmental service.

There is an overwhelming accumulation of ideas and perspectives identified in this research, and each participant harbors a vast analysis of each topic related to the study. I have had to be brief, narrowing down the big ideas and reflections that I gathered in interviews. It is an honor to be respected and offered the ample perspectives and life experiences that each participant provides; however, not every last word can be included for the sake of space and time.

The next component of analysis is to identify each sub-section with topics that are consistent with the voices of the participants, with critique and synthesis woven in between my field notes and observations, along with very helpful secondary sources. No one idea or topic of interest can be independent of another, as social issues relating to people are dynamic (Berry, 1987; Brown, 2009; Jones, 2008; Marouli, 2002). Each idea is woven amongst the other like a textile of information and insight. Data that is rich like this is impossible to silo - although for analysis, I have grouped the responses into four categories: life skills, leadership, education, and community development. Each of the major themes chosen is complimented with sub-categories that help shape the discourse and provide framework for the research (see Figure 1). 


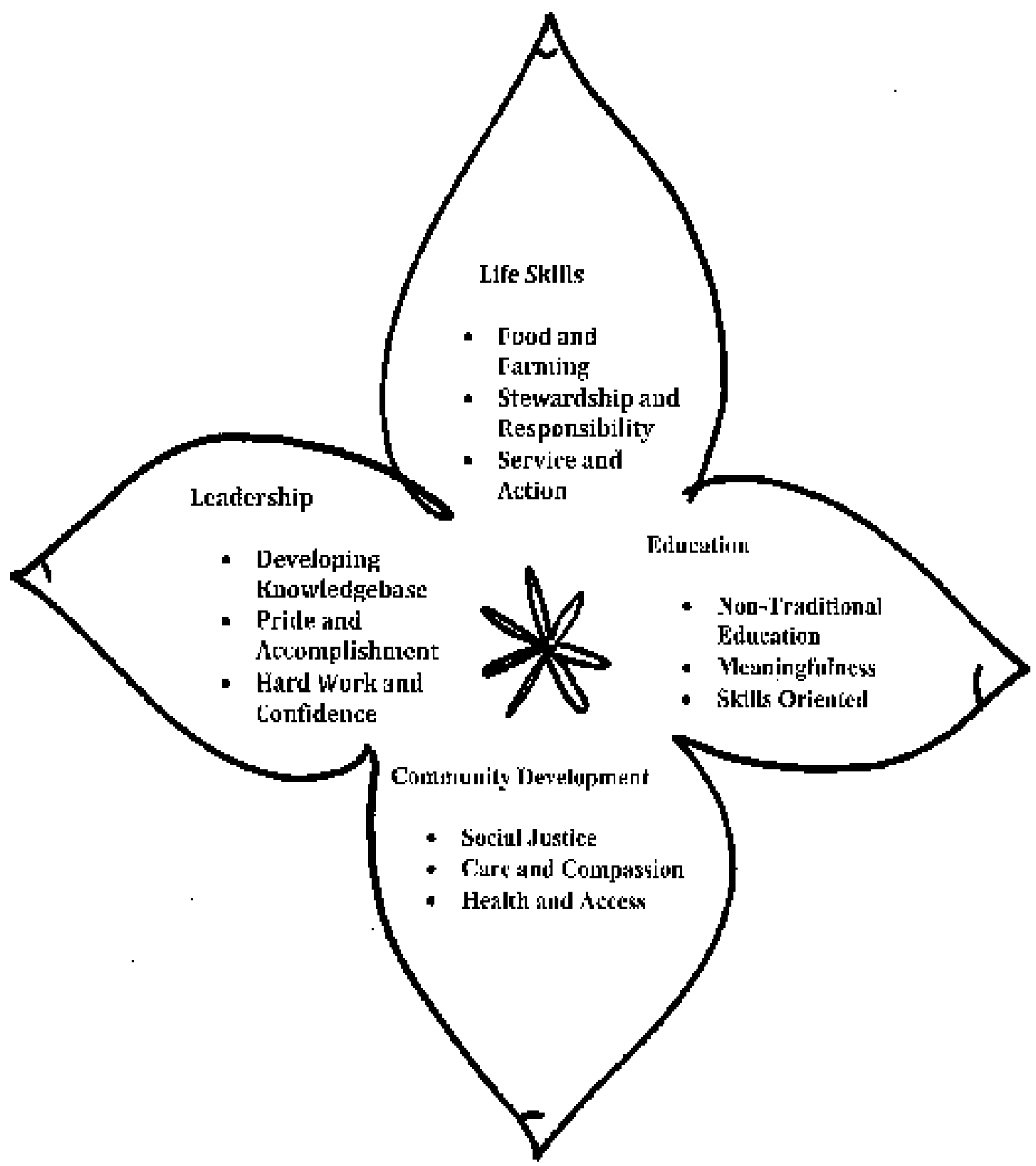

Figure 1. Dogwood illustrating four major findings.

\section{Life Skills}

Nontraditional, hands-on learning environments exist as a medium not only for learning and academic rigor but for practicing life skills that can be employed in multiple 
areas in one’s life (Fien 2000; Jones 2008; Marouli 2002; Tso \& Hill, 2006). As many of the topics discussed in this research underscore, multiple purposes for programming, literal and figurative understanding, leadership, engagement, etc. are critical for a foundation in acquiring tangible life skills represented by the first dogwood petal. The participants interviewed clearly state that the skills they learn connect to other areas in their life. The main topics and life skills that repeatedly surface in this specific section from the interviews are: food and farming, stewardship and responsibility, and service and action. Each sub-topic will introduce the voices of the participants and their emerging perspectives when asked if they had obtained skills that are tangible in other areas in their lives.

Participants' responses indicated that they identify with life skills in very different ways. I asked each participant if they thought they are learning life skills that they can use later in their lives, and the responses were diverse in perspective and their overall understanding of what life skills signify. Also, when asking about hands-on learning and programming, many ideas surfaced with responses around things that they can use later in their lives and when applying or working toward getting another job.

\section{Food and Farming}

The engine that operates both programs is food. My research suggests that food and farming or gardening are not only basic needs in providing local, nutritious, organic food to the participants, but at a deeper level, food is simultaneously propelling social and environmental action. Being outside in the natural elements involves environmental awareness and stewardship; meanwhile, serving food to others in a social setting (a soup 
kitchen specifically) braids the stewardship of justice among people and the non-human environment (Pelo, 2009; Raja \& Ma, 2008; Shiva, 2005; Thorp, 2006).

Walking into GRuB was inspiring. All of the chalkboards of tasks and objectives to achieve accompanied by a large kitchen and small farm out back, gave me the immediate sense that this was a farm for learning. Job Council provided a similar sentiment with the family-feeling of comfort and action that was also present in colorful photos and quotes, exemplifying investment and pride in their hard work as stewards in their communities. The participants also had multiple questions for me about where I work and why I decided to come visit their site. With shared interests between me and the participants, the interactions and discussions about food were deep and reciprocated with ideas and experiences.

My December $11^{\text {th }}$ field notes explain this relationship well regarding the participants' passion for and expertise with growing food and working the land. My notes state:

Wow, these two young men really care about this program. I just returned from a tour around the property and both (Aaron and Tim) have so much to say and share about the land and all that was and is in the garden space. They were as passionate about the trees and the green belt (a native space) as they are about the frozen over plants and wintered garden beds. It is evident that this is not only a place of refuge, but similar to home and a setting of comfort. Both men are very passionate about different things and provided so much information about the history, present, and future ideas that are designed for the garden. Was I just taking a tour of their workplace? What an amazing place for them to set sail in the world of gardening and working a farm.

My February $25^{\text {th }}$ field notes from Job Council match the above field notes and observations from GRuB in an enlightening way. The energy and excitement about food 
is inspiring from both organizations, and given that they approach the work very

differently, the responsibility and pride that each participant adopts is quite moving.

We head for Ashland from Medford to their community garden site, where they have been implementing gardens and cleaning up for the entire site. The group is split up into four small groups to discuss the need of food and the different reasons why people either do or do not grow food. The topic being discussed in a small greenhouse with 10 students inspires thought provoking discussions, involving historical and cultural connections to food and amazing ideas and concepts as to why people are unable to grow food. Those that have been in the program express the value in learning how to grow food, and newer participants challenge them with the practical component of time and energy that many lowincome families struggle with in regards to food security. I love the stories and dialogue that are surfacing; these young adults know their stuff and have no problem sharing.

Winne (2008) stated in his study on closing the food gap and the evolution of micro-enterprises and food/community structures that, "food, of course, tells many tales about people - their cultures, traditions, lifestyles preferences, homelands, and personal health” (p. 140). Similarly, cultural and historical contexts and relation to place are the under-story of each participant's canopy in his or her personal relation to food-before and after programming.

My questions about food and farming were very simple and developed over time with specifics dependent upon how a participant responded. It was clear that this was the engine of their work. It has influenced their eating habits, conceptualization about where food comes from, and confidence in addressing sustenance, along with the undoubted character transformation of giving fresh food away to those that need it. The quotes below provide evidence of the participants' perspectives:

I think, if we learn how to grow food now, and learn how to eat healthy now, we will eat healthier later in life and teach that to our kids. - Aaron 
I definitely feel more capable to do anything I set my mind to because they have given me so many different tools that I can work with that if I want to go off and be a gardener elsewhere I could do it, or I just wanted to do it for myself at home. - Maria

I think it is important that we help in a garden so that not all people need to starve. A lot of gardening has gone down hill because of companies taking over and farming land, like Monsanto. [Farming] Gives me a bigger picture of what [issues relating to food] are actually happening. Through this program I can find little ways in my community where I can actually help with those things. Even though it is not a big thing I am doing, if it grows it is helping more and more. - Larry

The generation before ours was getting down on the gardening and local food and now everything is coming from other places and nobody does anything. The real thing that I am helping is by creating the gardens. I think about things a lot and every time I am eating at places I wonder about where it came from. - Ranaldo

Growing food and tending the land are catalysts for other life skills that are obtained in either program. This is important for any multidisciplinary programming. Clearly these youth's participation in gardening and farming has taught them to be successful in other areas in their lives. For example, teamwork and the commitment to goals and personal achievement have stemmed from growing food and working together in a group setting. Feeling capable to do anything that one sets his or her mind to allows for confidence to develop in multiple areas of one's life. This exemplifies yet another connection that the participants are between social and environmental issues when discussing food politics and community action within the program and in their personal lives.

\section{Stewardship and Responsibility}

Stewardship and responsibility, as components of life skills, represent dynamic traits that relate to numerous areas in one's life. Stewardship amongst the participants in this research involves social and environmental conceptualization and efficacy to be 
responsible for themselves and as active members of their community. The participants'

responses are specific to daily routines, such as being on time, talking with people and presenting information, as well as being adaptable and confident in situations, for example:

I have definitely learned responsibility because before this job, I was soo...not responsible, I would get no homework done, I would do absolutely nothing, I would sit on my butt all day, and surf the Internet. - Olanda

Yeah definitely, getting to work on time, that is a big one. Pretty much working with other people, and some customer service type of stuff. When we go out and build gardens we have to answer questions, or even at market, at an event, or speaking about GRuB to people. Public speaking is a big one too. - Aaron

It helps them get jobs later, it teaches young adults work ethic early on and how work can be different in different environments. - Larry

I think that taking food home is really, really good [and] giving off [away] the food is not only for them but for yourself because it gives you the feeling of accomplishment that you have helped other people out. I think it is a great feeling, every time I give food away. Depending on how you look at it, you can think about looking at it as hard labor, or thinking about it as helping the community, while working hard and having a good time. We sell fresh food to people and when we go to the food banks and stuff, we give food to the people who don't even have a home. I would be glad to help others, and working the food bank, I like to do that. Serving people that are so grateful. And now that I know I am growing food and harvesting for people that are less fortunate than me, it makes me feel that I need to work harder, because they need help, and I want to help them. - Olanda

The last quote from Olanda specifically suggests that the responsibility in serving others food and being grateful for her own life allow for the development of perspective and self-reflection about her role as a steward. Olanda suggested that giving away food and serving others are multipurposeful in that she is serving others, working hard, and having a good time while doing so. Working with others that are grateful of her service encourages Olanda to work harder and be a responsible citizen. 


\section{Service and Action}

Service and action mark the third topic of the life skills petal. As both programs focus on food politics and empowering young adults as the agents of change, the dialogue is personal and thoughtful in each response. The discourse surrounding food is complex and weighted with experience in action and service amongst the participants in this study. The perspectives that each person shared about food and access were influenced by their own stories and relationship to food - many of the participants have gone without meals or have been victims of the global food market. Wekerle (2004) introduced the idea of “instruments of deep democracy” (p. 381) and conveys the role of marginalized communities as active participants in the food discourse and action. It is evident from the responses that the participants in both of the programs view themselves as instruments of action and service in the food movement's fight for access and equity. They are very specific about the industrialization of food, where it comes from and the necessity for everyone to have access to fresh, quality food:

We are working with something that is outside of ourselves. This [GRuB] is a charitable place where we help people out and the world. - Jessica

Giving back is something that is important now. I didn't understand a lot of issues and many have come out so I can see them now. It is a good thing to know I can help. Yes [we do learn life skills]. Helping people and by being in this program I really want to join the Peace Corps. - Matt

Pretty much every workshop that we do is a good skill or a good thing to know about; like hunger, or gender awareness. And it has influenced me. There have been some about weeds and identification [also], but I think the root workshops like life-skills and the kinds of job skills too [are important]. - Aaron

Participants in this study understood life skills differently, and their responses were both imaginative and creative. Youth can apply specific skills to their lives 
depending on personal variables and skills that have not yet evolved in their own lives. Both programs empower the participants to engage in food security and community outreach as hands-on, applicable skills to be adopted in different areas in ones life. Aaron's response suggests that he is learning to be of service while modeling traits of positive action with his perspective of gender-awareness and hunger. Aaron's comprehension of these topics and multiple workshops, which are components of the curriculum, enable him to move forward in action with an understanding of social and environmental issues.

Engaging young adults in a wide variety of topics and issues provides a foundation for better understanding the complexity of food and other basic needs. The topic of life skills is very broad and marries many of the traits that emerged in leadership development. Obtaining life skills initiates leadership with the eagerness to educate people about food and access (as explained in the first sub section) and with the responsibility to service and active stewardship in the program and in their personal lives.

\section{Leadership}

The second dogwood petal in the figure is leadership, with specific sub sections describing how leadership encourages the development of knowledge base, pride and accomplishment, and hard work and confidence. With feelings of accomplishment and a genuine understanding of one's potential in the bigger picture of citizenry, leadership ensues. Leadership (2010), as defined by Merriam-Webster's online dictionary is the “capacity to lead, or the act or an instance of leading." Many of the students declared that because of their experiences in either organization, they are more confident and willing to speak their mind, which are two foundational components of leadership. Some stated that 
they have taken risky steps, empowering them to reach beyond their personal comfort; still, others felt that they can raise their voice and be heard.

My field notes illustrate leadership and personal power within their routine.

Routine is critical in leadership and the responsibility to follow through with tasks and setting up for academic, extracurricular and personal success. The leadership training adopted at either program is multidisciplinary and tangible to every aspect of participants' lives. My field notes from December $11^{\text {th }}$, 2009:

I walked into this beautiful office that is the GRuB headquarters today, and there seem to be so many people there on a Friday - especially students, isn't Friday a night to go out and be a young kid? Students were there for their Friday homework session, and others were coming and going, participating in the end of the week tasks that any program or organization does. Given that this was my first time at the site, I wasn't sure who was a staff (well I knew a couple) and who wasn't. People prepare for the following day with group games and initiatives along with speeches for the upcoming event that Saturday to educate people about the program and what they do at GRuB. After about an hour, the organizational head informed me that two students would be taking me for a tour - yes, one on one time with my participants - finally, I am able to start this process! I was taken on a tour of the land, asking my thousands of questions - they are so patient with me. I learned the lay of the land and it is incredible. The students here really know their stuff and it is evident that they run the show. I can't wait to see their workday tomorrow.

This example is not only notable for the leadership present but for the structure of the program and how the participants are running the daily routines and program. While there are adults and supervisors on site, they are there for facilitation of logistics; the students drive everything else with pride, accomplishment, and personal leadership style.

\section{Developing Knowledgebase}

Before people can be strong leaders, share their perspectives and lead by example, it is necessary that they develop the knowledge to do so. In the case of GRuB and MYC, participants' development of a strong knowledge base in their personal and professional 
lives is critical. The basic traits of professionalism as defined by Maria, below, initiate her personal power to distinguish when it is necessary to be professional, and this demonstrates her development of knowledge. Other responses are more specific to understanding the natural systems and how these work, along with confidence, selfesteem and pride that one has for understanding and knowing something that others may not yet. Alison stated that teenagers need to learn about themselves and about learning in general. The quotes below are diverse and complex as to the definition of knowledge obtainment and leadership trait development:

They teach us different things, like how to be professional and like, what is the difference between professional and non-professional, and I get to use those at times, and it gives you common sense and the knowledge to know when to use which. - Maria

Whether it be working for the environment or doing anything else that helps, you learn about yourself and learning in general. It is something that teenagers need for their self-esteem that they are helping. I know more. More knowledge - I feel smarter. - Alison

It is nice to help your peers when they need it in school and anyone else outside of it. Your leadership grows when you have the knowledge of something that someone else doesn't - it is leadership. - Alison

The fact that I understand the real problems [associate with food] is important. Just to know that 2,000 miles is the average distance between the foods you eat and yourself is crazy. I think a lot of what we eat is way under what we could be doing. - Matt

I learned [in this program] how to identify different plants, animals, and trees in my area. [I have] More of a connection with the natural world. - Larry

Understanding that there is a reason for it [the natural environment]. You are kind of oblivious and I didn't understand the cycle of plants and the necessity of it and the unimportance of some of them. - Matt

Site visits and interviews revealed that the students in both programs love to share information about what they are participating in and learning. GRuB, specifically, 
encourages participants to go into their community and educate people about the issues they explore regarding social and environmental issues of food. Multiple students celebrated, in daily check-ins and in individual interviews, the pride that they held for being able to communicate effectively. It is important that young adults are encouraged to learn about big ideas and topics that affect people locally and globally, with a supported tier of communicating and delivering the knowledge to a wider audience. This relationship of educating the participants and initiating a knowledge base to support their personal power engages participants in expressing themselves as leaders.

\section{Pride and Accomplishment}

Like many of the topics, personal accomplishment and pride are elements of transformation in each program. The participants state that their participation in either program has changed their personal lives, their academic lives, and their home lives. GRuB and Job Council act as a home base for many of the participants with structure and accountability, countering the social and environmental challenges that they are accustomed to before their entry into the program. Again, big ideas and patterns of empowerment lead to confidence and transformative processes in one’s life and development (Delpit, 2006; Kozol, 1991; Pothukuchi, 2004; Pusch, 1981; Youniss \& Yates, 1997). All of the participants that I interviewed answered how being involved in programs like GRuB and Job Council is important for their personal development and current livelihood, giving them the confidence to be leaders and believe in their hard work. The only way to know that transformation and accomplishments ensue from programs like GRuB and Job Council is to ask and listen to young adult participants. This 
dialogue proved to be beneficial for their self-expression and leadership development as well.

Many of the main topics and subtopics in the findings of this research overlap. Most of the respondents noted that working hard and striving to be the best person they can be results from the confidence, self-management, communication, self-esteem, and strength obtained in the programs. The overlap highlights the necessity for quality programs to be multidisciplinary and aligned with trust and confidence.

The transformation that radiates from the responses illustrates that the participants are a part of something bigger than themselves, and, consequently, they are feeling a sense of accomplishment, purpose, and pride in their work. Grades have changed; perspectives have evolved, and the confidence to stand up for what they believe in as change makers are all testimony to the dynamic environments of Job Council and GRuB programs. Along with the structure and mission of re-creating one's life story and purpose as stewards for the human and non-human world, the participants are excited about learning and engaging in big ideas and concepts that are often neglected in academia and in their personal lives. Their words exemplified leadership in the vein of transformation and accomplishment in their hard work:

Leadership [is obtained in the program], an ambassador, to start my own thing like GRuB, I have tons of skills to help me do this. - Jessica

Since I have joined, it [my personal leadership] has become faster with risky steps. Before GRuB I wasn’t moving forward at all. I am moving 10-steps at a time now. I have definitely learned that I have more strength and courage than I thought I did. I can stand up for what I believe in. Before I felt that I had no voice and I feel that I have one now. - Jessica

I am working towards being a leader because I am some-what shy and GRuB has really taught me to raise my voice. I would like to share that I love being in the 
leader role, because when you raise your voice, things happen, and good things happen. I love spreading the word to everybody. I am here! - Olanda

This is the best thing in the world to me; it has totally changed my life. I would be lost without it. - Jessica

I think that taking food home is really, really good, giving out the food is not only for them but for yourself because it gives you the feeling of accomplishment that you have helped other people out, and I think it is a great feeling, this is every time I give food away. I was extremely shy, I wouldn't talk to anybody, I kept everything to myself, I was a quiet little mouse; I didn't do anything. I used to not care about anything, but now I stand up for what I believe in, no matter what it is and I will stand up for it, and personally I have built confidence and more respect for myself. - Olanda

I think has helped me to be more assertive. I don't act out as much as I used to. I have grown up as an adult. - Larry

I have seen a lot of people turn around because of this program and I am one of them. Before I had a GPA of 1.2 and I was doing really bad. - Matt

The voices that the participants have found in themselves initiate pride and accomplishment in their ideas and perspectives, as well as the belief that each and every one of them deserves to be heard. People can be shy and reserved; therefore, providing a safe place for them to practice their communication skills and reciprocated respect is important. Findings suggest that when young adults are empowered and listened to, this generates further engagement toward roles of leadership and responsibility regarding the subject specifically and in one’s personal life (Youniss \& Yates, 1997). Both women above shared that they have changed dramatically as a result of their experience in the GRuB program. The change is rooted in their voice.

Furthermore, purpose and accomplishment, confidence, and the motivation to work hard were all major themes that emerged as the participants' traits of leadership developed. As a follow up question to the outstanding responses, I asked a basic question 
that required the students to reflect on what life would be like if they were not involved in the program. The responses exposed the often harsh lives of the students before they entered the program and gave me a sense that they are not the only young adults that feel lost and unmotivated without structure. This only further proved that confidence and hard work in a multidisciplinary setting are worthy for discourse.

\section{Hard Work and Confidence}

Hard work and confidence are capstone traits of leadership. Working hard with the earth and having time to self-reflect and gain a perspective of earth-centered principles and levels of social stewardship have provided the participants with confidence in themselves and their work. The interview questions that I asked were not specific to hard work or confidence. Initially, I was most interested in their perspective of leadership, and specifically their role as leaders - and how this affected their lives in the program and outside of the program in their personal lives. Their responses portrayed that hard work and confidence render positive personality traits as a leader:

Public speaking. I probably wouldn't have volunteered to be interviewee for this because I was really shy before-hand and they not only teach you how to publically speak, but more effective ways of communicating and getting your point across. I guess just all of the skills that they teach you. It gives you a lot of confidence to be able to lead and take that initiative for yourself and be able to take it into your own hands. Fundraising, and talking to people on the phone and just a whole bunch of stuff, like cooking and stuff that can be used later in life. Synthia

I guess it has helped me to inform people that there are other options. - Larry

You teach people - it is entitlement; I want to teach my kids to garden and learn these things. Since I am African-American, they [other students] think I am this crazy loud mouthed chick, that is a ghetto girl - "don't look at her weird because she is going to freak out on you," but that is not how I am. I call people out when they are not being cool, but I won't be mean to them. I help out in the classrooms a lot. - Justina 
You know, it is your life and you are doing all of this hard work, and you have more security in the fact, that you can do that kind of work and what you need to and feel good about it, and just yourself esteem goes up a lot and the trust they put into you makes you feel good about yourself and makes you want to do better. - Synthia

Yeah, in this program I have learned a lot about self-management. Before this crew I was angry, I couldn't control my bi-polar, anything would make me mad and I would snap. People see me now and they are like, you are calm and more down to earth, and that is why I like this program, it has helped me find myself. It is great. - Justina

I feel stronger as an individual. I feel that I can stand up for myself more and communicate better with other people. I used to have a big attitude problem and Job Council has helped me a lot with that. - Cheryl

I have definitely seen it give more confidence to people and that definitely helps with everybody's life to take the initiative to get what they need. There is a lot that goes on, and depending on your career choices are, there are a lot of things taught by gardening. - Synthia

Justina and Synthia shared that they have been able to use their skill base from

GRuB in their academic lives at school. This illustrates their confidence and courage as leaders sharing information. Justina and Synthia are from different programs yet are consistent in their perspectives. Synthia is from a family of previous GRuB participants, and she has adopted the idea of leadership and personal power to a community level that many others I interviewed are striving to attain. Her wisdom and leadership illuminate every word:

I did become more assertive into ASB [associated student body] office, I had a lot of ideas about how to help our school this year especially with our cafeteria food and making it easier for new kids coming in, and last year I wouldn't of done that. I did do one thing last year, where I made it so that our school would have breakfast, but I was really scared and nervous about it and talking to people, and this year I was able to talk to my teachers and principle - talk to them on the same level, as a person and not an authority figure, and be more comfortable with myself. - Synthia 
The responses and conversations I had with the participants exhibits their confidence to speak their minds and share information. This confidence derives from a multidisciplinary, educational byproduct of their hard work learning about food systems, environmental stewardship, public speaking techniques, and group development with their local and greater communities. As a result of their participation in such programs like GRuB and Job Council, all of the participants’ responses included a critique of formal education. They shared that their experience of working hard in either program has given them confidence to critique the education system and celebrate nontraditional models and the expansive ways in which learning can take place. The next dogwood petal outlines education with quotes and analytical discourse.

\section{Education}

The participants' insights into youth engagement, leadership, attainment of lifeskills, and community development instigated further analysis of nontraditional education. From the first to the last interview, the participants shared how important their current form of education is for their personal academic success and feelings of accomplishment. Education that is hands-on and relevant proved to influence both their demeanor and understanding of education, represented by the third dogwood petal.

More often than not, nontraditional students who are not succeeding in school are struggling with the traditional model of academia that is oriented to a specific learning style, often neglecting the progressive, respectful relationships that can exist between the educator and the student. Programs like Job Council are located in the school as a period in the school day at Medford Opportunity Alternative High School, providing an outdoor experience to learning and engaging in academic, hands-on curriculum. GRuB is also a 
school accredited program although it is an after school model simultaneously serving as a safe place for students to be during after school hours and a nontraditional learning environment of engagement and critical analysis of food systems and social integrity. I asked questions in the interview that explored the program's models and structure, yet nothing was pointed specifically at traditional versus nontraditional education models. The theme of education and the academic needs of the students evolved in time with specifics of the importance placed on learning in a hands-on environment. With flexible learning relationships amongst the teachers, program staff and participants, rapport and trust becomes vital in their success and investment (Deutsch \& Jones, 2008; Kanter, 2001). The more the participants were asked about where they would be without a program like Job Council or GRuB, or what keeps a person coming back everyday, the real discourse began with a dialogue of real-life experiences in academia. The education petal discusses nontraditional elements of education, the meaningfulness and care amongst the theme, and the skills-oriented that serve for educational rigor and life skills.

\section{Nontraditional Education}

Unfortunately, young adults, specifically nontraditional students in a traditional environment, easily slip through the cracks. Larger class sizes, national testing standards, lack of support for educators, and ancient teaching practices and instruction are amongst the plethora of factors contributing to why young adults are either forgotten or missed in the public school system. With programs that provide an outlet for learning and building relationships amongst a milieu of selfless behavior, change occurs, and students are given a purpose (Youniss, Mclellan, Su, \& Yates, 1999). Once I asked what students would be doing if they were not engaged in a program like GRuB or Job Council, they provided me 
with a perspective of their lives before their involvement with either program, as well as a critique of traditional educational settings:

Everyone is struggling to graduate....they don't have time to think about their community needs other than what they need and what their school needs. What we do at MOHS is branch out and this program branches out to other people, [specifically those] who need what we can offer. If every school had a program like this, think how much healthier the environment would be and all of the students would be. They would be in a better place in school, [and] in the community to be able to help [helping people]. I think it would be amazing. - Alison

This is a lifesaver. It is such a safe environment unlike the environment at school. It seems like people care here. In high school people just want us to move on. This is a change from a lot of the things out there. It [the games and hands-on activities] makes me think that I can do anything and work in the field. I like changing schools because they were more GRuB oriented. - Olanda

Because we have knit together such a close family we just automatically have emotion in there, really deep emotion. And we have workshops so that we can try to help each other out and have discussions where someone will put a question in anonymously and everyone else will try to help them out. - Synthia

I wanted to turn my life around and try something new. It is not all classroom work, we actually get to go out into the field and do great things in the community. I like the gardening bit, I like removing invasive species, it is like a family thing. All of the kids know each other really well and we are working with each other for two hours a day, it is different than classrooms around here. I noticed that a lot of kids want to skip because they are not really into what they are doing. They feel like an everyday person, they get taught the same thing, they don't get help, and it is hard to be pushed through a system when you are not learning anything, you are just going through the motion. After a while people are like - motion, step, jump through the hoop. Yeah I think it would be nice to see other kids get the chance to get out of the classroom, and actually learn what they [traditional students] learn in a text book, out in the field. - Larry

I wish they had a program like this in every school. More kids would be able to stay in school and be in school. It would boost our future if everyone knew about how bad the government, how corrupt it is and how they are putting pesticides into our food. - Justina

It was knowing that I could do something in school, get credit and get something good out of it - get real life experience. I think this [high school] is when many people lives turn because a lot of their problems are surfacing. Actually a lot of 
people I know would be doing bad things with their day, not graduating, not working. - Matt

I think it would make schools a lot better and kids like to be outside. My friend just joined Job Council and he is coming to school a lot more. Kids get bored in the classroom and out here you make friends that you will have all year long and there are no cliques or any hate going around. In big schools, you don't even feel recognized. Here it is like, Job Council, I get to go and kick it with my crew! - Cheryl

The responses embrace perspectives in second chances, the honor of giving back, opportunities to use the skills they learn in other academic classes in school, safety, familial bonds, being outside, and the overall accomplishment of helping others. I witness this each day I teach in an outdoor setting. It is inspiring to hear the participants provide evidence as to why a nontraditional model of education and learning is productive for their academic success, learning style, and capacity to succeed. The responses warming and inspire educators who understand the necessity in a shift from the modern paradigm of education (Delpit, 2006; Kozol, 1991; Kugler, 2001; Sterling, 2001). The participants have obviously found meaning and pride in their experience, propelling them to respect and honor education that supports their learning styles.

\section{Meaningfulness}

The participants shared that their experience promotes a sense of meaning and purpose. Because the curriculum and structure invite one to think critically about real world issues and subject matters, students embrace their work and stewardship with pride and value. Participants I interviewed explained how their participation was humbling and worthwhile. I asked where they would be without their specific program, and their responses suggest that they would be less likely to care and give their time. One student stated that she is not just taking from school; she is giving back. Along with stewardship 
and meaningful engagement, participants also stated that they find meaning in their

personal development and transformation:

If everybody learned to grow organically and loved the environment then our future could change into a more environmentally friendly thing, instead of this polluted world. - Justina

We are not just going to school and taking from it, we are giving back to it as well. - Jessica

[Without the program I would] Probably off being self-absorbed and like everyone else you know. They wouldn't go off and try to make a difference, they would be at home watching TV or just making sure they are okay. - Maria

[I was] In trouble all of the time. Or some of us, not all of us. I don't think all people would be as friendly either. They would stay in their shell. - Aaron

At a regular school still struggling. I was struggling before this program and most people were. - Cheryl

This section of responses illustrates that education is to be taken seriously and curricular goals of meaning and reciprocity matter to the students. The participants value their evolution and place in education and recognize that they are in a better situation with less distractions and more purpose. Many of the participants have been underserved coupled with negative relationships that have affected their place in education; however, with the programs' positive learning environments, they have regained their pride and identify because of the skill oriented and shared vision amongst their peers, instructors, and community members.

\section{Skills Oriented}

The skills obtained in both programs are considerable. In every interview I asked the participants about the applicability of life skills they are learning to other aspects of their lives, as well as the relationship gained with the natural environment. The responses 
suggest that they are learning skills that are multidisciplinary and germane to many areas in their lives. Similar to the responses related to life skills, the participants recognized that their service and time in either program are teaching them social and environmental content that is vital to their present and future success. An important aspect of both programs is that they promote not only the hard skills of tasks and projects but also the soft skills of emotional awareness and personal resiliency. Examples of the skills oriented from their experience are:

I was a kid that had no idea with nature and now that I am out here everyday we learn something crazy about nature that I didn’t know before. - Ranaldo

You learn a lot of important things when farming, like the different processes. You have to work as a team. So, I think that it [the life skills obtained] is farming, but there are skills you can carry on to other things. - Jessica

I can apply some of the things we have learned here to my biology class or like, debates, anything - you don't realize that until you actually use it later. It is so useful and it has helped too with what I want to do in the future. It helps you discover who you are, and maybe even a new career path. There are not many places that will give you that second chance. There are other people that I have influenced at my school and they see that there is more to what is going on in the world than they think. I am currently going to give a speech in my English class, a persuasive essay, about something about hunger and I didn't even know most of the statistics until after I had gone over it in GRuB, and it was eye-opening and I think it will be like that for them too. - Maria

Again, the participants' responses are vital for understanding why garden-based, community projects are important for young adults and their success. Maria stated that she has applied what she is learning to multiple areas in her life. She is encouraging people to understand the concepts and ideas that she has learned from being a GRuB participant. The skills that develop from the educational structure of both programs align with confidence, accomplishment, meaningfulness, pride and many other topics under investigation in the findings sections. Overall, the participants' responses 
overwhelmingly affirm that they are learning skills combining social and environmental stewardship with community action as a result.

\section{Community Development}

The final dogwood petal in the findings represents community development specifically addressing social justice, care and compassion, and health and access. Serving the community is what ties the social and environmental piece together simultaneously; the participants are working hard in the field, intentionally serving other individuals who are underserved in society. Serving community members enables the participants to interact with and assist others while building confidence and pride in their role as leaders. The data collected address multiple elements of service. Shiva (2005) articulated service and community as “receive[ing] nature’s gifts and return[ing] the debt through ecologically sustainable lifestyles and earth-centered cosmologies” (p. 22). The service and community development work accomplished at both sites focus on caring for the earth and the gifts of nature - seen and unseen, paying back the necessary debt to those in need and modeling an earth-centered cosmology approach.

The earth-centered cosmology is engrained in each quote shared by the participants, along with those that I observed. The call of duty mentality resonates in each participant’s personal insight of his or her individual program.

The mission of both programs is to connect participants with the greater community through service and stewardship. It is something that the participants acknowledge as vital to their intra- and inter-personal success. The feelings of accomplishment, influence, communal ties and bonding, service and perspective are central themes from the research and inquiry of community service and action. 
Perspective and compassion for others are other integral themes that evolved from community discourse and reflection of the place-based learning experienced at soup kitchens and serving others - including themselves in the strain of justice and social responsibility.

\section{Social Justice}

The chief perspectives from the participants interviewed are the economic, social, and environmental costs of food. Nobody with any drive for justice wants another human being to starve and be without food; however, so many of us are removed from those that are this desperate. Both programs are realistic about the ways people live and the limited access that some people have to food, drawing in responses of compassion and purpose.

Another consistent theme amongst the participants I interviewed was critical analysis of the food industry. Topics such as food travel miles and invisible transportation cost, genetically modified production and corporate control, and the generational shift of farming and food production suggest deep analysis and understanding of food on a global scale. The participants' responses to social justice and community interactions were:

It [serving at the soup kitchen] makes me feel like we are influencing people. - Ranaldo

We are growing things we need together and I think it creates a great bond between people. A lot of learning [happens] and we are really distant from people that we live around, specifically in problem areas, we are extremely distant. It brings a community together. - Matt

The consistent emerging theme is that real relationships form and evolve between the participants in both programs and those that they serve. The unrecognized elements of service and community are the accomplishments amongst those serving and those being served. I have become aware as a researcher that the foundation to open classroom 
discussions, councils, and workshops is to identify equal accessibility of fresh food. The discourse considers more than opinion and respecting what is right and what is wrong socially, for there is a personal piece that exists in the participants' responses, particularly since some of these young people go without the basic needs of food and shelter in their own lives. This provides insight to each response with real life perspective. The camaraderie established and the detachment of victim-based mentality is an empowering component of both programs. Their experiences diminish stereotypes, and empathetic relationships form as a result:

And once I got there [the soup kitchen] I was like, "these people, they are nice people - sweet people" and the economy has wrecked them, totally wrecked them and I don't have it as bad as I had thought. I have a house, a place where I can cook, a warm place where I can sleep, actually a heater in the winter, and an AC in the summer. They [those they serve at a soup kitchen] just take what the weather gives them and they have it worse off. - Olanda

I know a lot of the kids here help out their parents paying rent and stuff and so if they could even get a job, then they would be putting their money towards that, and if they couldn't, some of them might be having some serious problems meeting ends for rent or maybe even homeless at this point. I know a couple of us are at that point, where we need to get a job right now so that we can stay in our house. My family has always had problems with getting enough healthy food and just food in the house, but I don't think about it that much about actually being available to other people. - Synthia

[Be] cause the issues we deal with, is basically hunger, not just doing something nice or something to learn from - it is making it so that people have food to eat. Most of the time we forget about those people, and if we are able to give food to eat and take care of ourselves, we don't usually care about our neighbors or other people. - Maria

I think there would be a lot more peace because there wouldn't be fighting over food, and people would learn to get along with each other, like de-escalation skills, and pretty much skills that help to build up a community, [by building] a healthy safe community. - Aaron

It gives them something to look forward to and something to be passionate about, and to learn about. It [food security] is such an issue and there is so much that can 
come from it, good and bad, it is like a doorway for people that don't really have anything to believe in or food in their bellies. They are learning that food, if you are growing it yourselves, can support yourselves with food instead of not having anything. What if they could have their own garden someday and live off not a lot of money, but eat their own food. [A relationship of] Kinmanship is formed and you get to relate to that person, and you know, times are tough. Understanding [I understand the relationship] between people and learn that I am more fortunate than a lot of people. My family never had to take me to a food kitchen, so I am fortunate in that way, and helping them makes me feel good and it helps them out. - Alison

I think it helps bring people together as a whole; they get to help each other out. - Larry

It is really empowering. To see that even people in trouble can still help other people. In turn, it makes us better. I have seen a lot of people turn around because of this program and I am one of them. - Matt

Stereotypes dissolved for the participants in their soup kitchen experiences because serving others gave the participants a sense of purpose and accomplishment, providing greater perspective (Youniss \& Yates, 1997). The relationship between lowincome students serving those who rely upon a soup kitchen for food binds a community together. The experience of service initiates real-world relationships, exposing issues that are prevalent amongst many low-income populations. The reality in which people live and the camaraderie, or as one-student stated, the kinships that evolve in this relationship negated the victim mentality and generational poverty that their community existence often perpetuates. The bond of empathy, care, responsibility and inter-generational learning influenced the students to see the world as a community of people - instead of separate individuals.

\section{Care and Compassion}

GRuB and Job Council purposefully work with young adults on issues that relate to real-life, controversial components of everyday people and communities. Due to the 
subject matter and the structure of being a steward to the land, as well as with a purpose of providing for others, their role as leaders is taken very seriously and with immense pride. GRuB specifically provides training and skills that promote leadership in multiple social arenas as well. Giving young adults a sense of purpose encourages leadership (Saunders, 2006; Younnis et al., 1999). Two participants clearly explained that their specific program has taught them to care for others; meanwhile their sense of place is an additional avenue for leadership in other areas of their lives. For example, participants from each program illustrated the essence of awareness and accomplishment, which teaches diligence and perspective:

This program really helps us be aware of the people around us and it teaches us that people needs us in a way - we are not just doing this to get money, there are people that count on us. - Maria

We all get to do these projects where we get to help the community, we get to help the earth and we help people too. - Alison

We are working with something that is outside of ourselves. This is a charitable place where we help people out and the world. - Jessica

It [farming and gardening] brings people together, community members together. Learn new stuff and make new friends. - Cheryl

All too often urban youth are denied access to environmental and pastoral outings of recreation, stewardship and exposure (Jones, 2008; Louv, 2005; Pusch, 1981; Thorp 2006). The lack of exposure is exacerbated by both the lack of value that we place on the natural non-human environment, as well as the industrialized model that has shaped the American (specifically) city into a concrete jungle (Berry, 1987; Orr, 2002; Shiva, 2007; Wekerle, 2004). Most of the participants interviewed shared their experiences working outside and acceptance of the natural world as a teacher and provider. 
Job Council is a two-tiered program that not only works on garden projects but works on restoration and site management projects that connect the participants to the outdoors in multiple settings and educational venues. GRuB's site is in an outdoor, tucked away space that cradles the farmhouse and has a small creek that the GRuB participants restore, called the green belt. The connections that I observed from photos I had taken, along with interviews and field notes, is that the participants of both programs have fun outside and value their time in the natural elements. As a result, there are deepseated relationships formed, which provide evidence of how much they value the environment and their role as stewards for the natural environment's well being. Examples of care and compassion for the natural environment are evident in participants' voices:

Farming the land is taking care of the land that we grow this food on. This land was stolen years and years ago from Native Americans, and we want to return it best we can. We are always putting up buildings, which is taking away from the land, and creating soil erosion, which is making the earth go away. We want to heal It. - Jessica

I have definitely been more compassionate about it [the natural environment], because before I used to take everything for granite. Trees help with air, and I have learned so much from the environment and I can respect it more than I have before. Before, I hated being outside. I think that gardening as a young adult has helped me, to be more compassionate towards plants, animals, people, and it has really changed me. - Olanda

I definitely appreciate it [natural world] more, I didn’t realized how much we had abused the land before, and how little area there is for us to actually produce food, and it makes me really appreciate it when I do see areas that do have food. The land gives so much to us and we abuse it all the time. - Maria

Overall I want the environment to be healthy but at the same time I want people to respect that and respect the environment. And I know so many people that litter and do all of this stuff that they don't think matters, and it really does and they don't realize that if they were to respect the environment more than that respect could go back on them and they could respect themselves more. I have always 
been into being outside and I think I took it for granite, but now I see the beauty more and what surrounds me and I can appreciate it and care for it. - Alison

Spiritual. I feel more connected with the earth and it taught me a lot about myself. I was lost and now I have opened myself up. I feel like I know myself more, before I didn't care about anything. I try to spread the word because I feel that not many people care about it. To say it is one thing and to make a difference is another. - Cheryl

The theme of the responses with regards to the natural environment is holistic and centered on care and compassion. My interview question was very basic in asking if the participants' relationship and understanding had changed since working with the land.

Each respondent valued one of many themes: connection to land and place, historical context and cultural components, and spirituality. Once relationships form, and people rely upon the quality and wellbeing of something, the holistic component evolves, and a deeper understanding emerges. Also, with a complex understanding of the natural environment explicitly in the responses, it is notable to add that the course content and themes that are studied include an exploration of the past, present, and future of food and the land.

Responses of passion, compassion, history, spirituality, honor, and interconnectedness were amongst the major themes that evolved from their perspectives working outside, learning about the natural environment - all with food as the catalyst. The participants were attentive to the natural systems, an attitude from which compassionate and caring relationships form.

My question regarding the natural environment was simple and sought to learn more about how their relationship with the earth and working outside has changed since their participation in either program. Some had never spent time outside before; while 
others had grown up with a commitment and relationship to preserving and caring for the natural world. Most of the responses I gathered from participants provided a foundation, for me as a researcher, to understand their connection with the land and what honest themes arise when asked with simple terms of inquiry. It became apparent that the natural environment and growing food is a basis for deeper emotional relationships of value and reciprocity. As exemplified above, there is an array of diverse responses providing a deep connection and appreciation for the earth and our role as humans living on it.

Civic engagement is residual consequence of the skills participants develop and employ in both organizations. As Wynne (2006) and Schneider (2007) stated in their literature that in regards to civic engagement, social capital, and civic agriculture, each topic of discourse apparently relates and marks the leadership development and voice that is encouraged in both programs and contributes to their identity and transformation as young adults serving others and themselves simultaneously. While the participants that I interviewed provided a copious amount of information about their role as leaders serving others and preserving the natural environment, they were also serving themselves.

Each student reflected that they feel as if their experience is a way for them to learn about themselves and the topics of gardening, working with the earth, and serving others. Students are feeling smarter and more assertive in their role in society and their role as caregivers. Noddings (1992) boldly asserted her perspective of care as pedagogy. "We are cheating those who might genuinely care for intellectual work and the world of ideas” (p. xiv). Giving underserved young adults an opportunity to care about the world and to give their time and energy to something is the catalyst to their transformation and achievement in either program. Because food is a central theme in either program, the 
next section will share perspectives from the participants in regards to health and access of whole food systems and serving others.

\section{Health and Access}

Wynne (2006) noted that civic-agriculture and community based learning influence people and their relationship to the land. Programs that incorporate food as a focal point allow for participants to "see that food is a tool that enables them to think about the world with a new lens” (p. 225). Food is powerful, and due to the undisputed relationship that everyone has with food as a basic need, it provides deep contextual relationships that inspire the change, evolution, and leadership that have surfaced in this research - promoting health and access for everyone. Each person's response is very specific to community needs and themes of accessibility, which were also strongholds in their classroom and round table discussions that I witnessed when I visited each site. For example:

I think it is important that we help in a garden so that not all people need to starve. A lot of gardening has gone down hill because of companies taking over and farming land, like Monsanto. [Farming] Gives me a bigger picture of what [issues relating to food] are actually happening. Through this program I can find little ways in my community where I can actually help with those things. Even though it is not a big thing I am doing, if it grows it is helping more and more. - Larry

The real thing that I am helping is by creating the gardens. I think about things a lot and every time I am eating at places I wonder about where it came from. Ranaldo

I definitely love to give away food for free. It is a right you know, it is not a luxury. All people should get food. If there is someone starving for food you should just give it to them [people in need], no one should be without it [food]. Plus, you start caring about the farm and you are like, this is my home; you want to come back to it all the time. If I want to go off and be a gardener elsewhere I could do it, or if I just wanted to do it for myself at home. - Maria 
Instead of building all of those large skyscrapers, they could grow food and have a farm. Ever since I have worked here I have learned to like food a lot more, because like, all of these new vegetables that I didn't know were there. They taste better than nasty processed stuff that you buy at the gas station. I am not as hungry as much either, because I can grow food. - Aaron I think that definitely growing your own food, is probably the healthiest you can do because you can't grow candy out of the ground. So growing carrots and lettuce and whatever, it is very healthy and there are so many processed foods, and it just, goes the opposite way. It is gross in the grocery store, and there are so many chemicals added to vegetables and fruits, and to make them a certain color and I would really rather have natural food instead of food where I don't even know where it comes from. I have definitely eaten well since I came here. - landa

If our world does go to hell and the factories are down and we have no fossil fuels to help to do all of the manufacturing of food, we can just go and plant our own food and we learned this when we were in high school. You know what is going in your body [when you grow something yourself] - you are not ignorant. Justina

The farming helps our food source and helps us have more food that we need because the economy sucks and it helps people because they are out doing something or making their own food. People know what is going in their body if they are growing their own food. If we don't plant our food then we won't be able to eat. - Alison

It has definitely made me more healthy. It is hard still because healthy food is really expensive to buy. It has given me more ideas on what to cook and I wouldn't cook at all before I came here and now I can actually cook some things; really tasty and healthy food. It has given me some insight on that. - Synthia

I have always wanted to be part of the community, but I didn't really know how to do it. It gives something back to help the community, for sure. Definitely makes you feel like a better person, and inspires you to do more and keep helping people. As far as further community goes, I know we help out a lot of people and I think that everything would be a lot worse if we weren't giving out food and it would really suck. - Synthia

Ultimately, the participants suggested that young adults are vital in community-based projects. They are young, have the energy and time to serve others; furthermore, when given the necessary context for change, they are diligent and willing to lead. All four topics - life skills, leadership, education, and community development -overlap and 
merge with one another because of the nontraditional, multidisciplinary approach to education that both GRuB and Job Council programs adopt.

Life skills ensure that participants can use the content of the program in other areas in their life. Leadership enables the participants to act on the life skills obtained and provides a base of confidence and courage in their role as change-makers. Nontraditional education supports their academic success while learning about local, national, and global issues that relate to social and environmental action. Overall, community development is the context for change and caring for others and building bonds across cultures and classes, ensuring that people have access to their basic needs and that health and justice are priorities.

Young adults possess wisdom and knowledge of their participation in programs that positively influence others and themselves. The participants' responses and quotes clearly illustrate that when asked their perspective, they share information rich with insight as to the importance of young adults engaging in community-based food projects. It is important that researchers continue to directly ask this population in order to better relate the needs and wants of similar programs and their participants. 


\section{CHAPTER V}

\section{CONCLUSIONS AND RECOMMENDATIONS}

\section{Conclusions}

It has, however, become increasingly important that the town's young people have an alternative frame of reference that doesn't include the local mall and that gives them a respite from an economic system that treats them as if they are only consumers in training. A hand plunged into freshly tilled soil, the squiggle of an earthworm, or a tiny seed mysteriously transformed into a green life force were, at the time of the farm's inception, experiences fast approaching the brink of extinction. (Winne, 2008, p. 55)

Every person in the world is worthy of fresh, quality food. However, as local sustainable food practices surface to a mainstream audience, the low-income populous in this country and all over the world, remain ignored. While food is becoming a class-based issue of privilege, underserved young adults are being denied access to real-world, big ideas associated with bettering themselves, their community, and the non-human world in regards to growing their own food and the policies that are associated with food (Thorp, 2006; Wekerle, 2004; Winne, 2008; Wynne, 2006). The findings from my research reaffirm that young adults need to be heard, that after-school and academic environments should employ nontraditional pedagogy, and that a caring and responsible milieu replaces the traditional, hierarchal models of teacher-learner relationships (Delpit, 2006; Freire, 1970; Noddings, 1992; Youniss \& Yates, 1997). Food, in this case, is one avenue toward change, marrying the environmental and social issues simultaneously. 
The central subject in this research is food and access, with young adults as stewards to the human and non-human world by growing food and serving their community. Not only have the young adults in this study enlightened me with facts and perspectives, but their role as change-makers at the community level have included overwhelming responsibility and care for themselves and the earth.

Noddings (1992) acknowledged the necessity for a pedagogy and approach to learning that is centered within the ethics of care. Care as a central topic in this research supports Noddings's findings and theory, recognizing that everyone learns and understands ideas differently and that even with these differences, people can learn from one another and evolve as individuals in a larger community of people. Noddings noted that inclusivity is vital in education and both programs in this study provide a learning environment that meets the needs of a diverse audience, along with the multiple learning styles that are amongst the participants. For example, Noddings stated:

As we consider how education might be organized around domains or centers of caring, we have to recognize that people take different perspectives on each of these domains not only because of individual interest, but also because they belong to different races, nations, sexes, classes, and religions. (p. 47)

An important conclusion to note is that both GRuB and Job Council programs provide a learning environment that is diverse in content with care as the catalyst for a relationship with themselves, their families and the earth, and the inherent connection that surfaces in growing and trusting the earth and their community, as well as an in-depth understanding of access and privilege.

The theory of inclusivity in the environmental movement that Jones (2008) presented aligns with the practice of both GRuB and Job Council. It is critical that 
growing food and serving the earth as stewards are activities that all people from all cultural backgrounds need to be engaged in for the health and well being of the entire community - human and non human.

The themes in Figure 1 and the analysis indicate that young adults understand the issues surrounding food systems and community interactions. The participants' statements and quotes in either program provided evidence of the importance of young adults, specifically as agents of change in projects relating community and food. The interview questions I asked provided a base for the young adults in this sample to celebrate and delve deeper into the ideas of food and access. Each student indicated that the multidisciplinary approach to their learning benefits their personal and professional lives and that the skills obtained are many.

The traditional models of education and pedagogical approaches no longer effectively engage students, and these need to be readjusted to meet the needs and wants of the youth in the system. The research here clearly demonstrates why young adults believe in this necessary change and how by working on projects that are important to the livelihood of other people, they are empowered to change their lives and better the world.

Multiple programs have provided avenues for people of all ages to grow food and serve their community; however, there is a lack of research from the perspective of young adolescents and their experience in community based projects, specifically from those that live below the poverty line. To better understand the needs and the wants of all people in garden-based, cutting-edge programming, young adults deserve to be engaged and empowered to openly express themselves and share their experiences through story and dialogue. This research has shown that when engaged, young adults have an in-depth 
comprehension of major themes that are associated with their specific programs and real world, big ideas. Change happens. If educators, administrators, after-school professionals, and youth advocates want to harness this population and find solutions to economic strife and environmental exclusion, it is imperative that young adults are understood, listened to, educated, and consulted with about their lives and thoughts regarding community revitalization and movements of change.

\section{Recommendations}

I suggest, from the insight and perspective of the young adults I interviewed, that young adults continue to be conferred with in their roles and ideas involving the specifics of a program or model. Youth are the future, and society needs to trust their insight and foster their rigor in discourse, including a shift from the current top down approach to community revitalization toward a grassroots, inclusive milieu of change and empowerment.

Young adults desire a role of responsibility and motivation associated with realworld, meaningful events, while being a part of caring environments (Noddings, 1992; Younnis \& Yates, 1997). Food, specifically, is a topic that relates to everyone and involves caring for the economic situation of those who are underserved, encourages people to face the environmental injustices in their lives, builds relationships with the natural world while being hands-on, and creates a reality of the social welfare of those serving and those being served. Working hard and serving others provide a space for lifeskills training, transformation, community capacity and engagement - all while dissolving the victim mentality that often exists in low-income communities. 
We are at a pivotal point in history in which change and alternative models of educating and serving others are vital for environmental, social, and economic welfare. Promoting responsibility that serves young adults in after-school and alternative academic settings and programs is essential to inclusive environments that encourage sustainability of programming and progressive educational models. My recommendations for a sustainable foundation in alternative programs targeting low-income, underserved young adults are to compensate participants in the form of money or scholarships in order to ensure that they can meet their basic needs and that they feel their time is taken seriously.

Youniss and Yates (1997, pp. 135-153) have suggested 10 ideas be included in designing and implementing programs in a youth advocate program, particularly relating to community service and responsibility, in order for a program to be successful and conducive to the lives of the participants. My recommendation, after researching both programs and learning about the essentials of a successful food movement and youth advocacy program, is that the ideas below be understood and included in future programming at any capacity. The 10 ideas for designing and implementing communityservice programs as suggested by Younnis and Yates are: (a) Meaningful activities, (b) Emphasis on helping others, (c) Integrated part of articulated ideology, (d) Group rather than individual action, (e) Reflective opportunities with peers, (f) Service organizers as models and integrators, (g) Site supervisors as models, (h) Acknowledging participants’ diversity, (i) Sense of being a part of history, and (j) Responsibility.

These suggestions are catalysts to the caring and compassion component of 
Noddings' (1992) model of education and teacher/learner relationships. They are also noteworthy for future educators, administrators, youth activists, social workers, and young adults. The 10 recommendations also align with the inclusivity and need for diversity that Jones (2008) marked as valuable for any sustainable movement. The programs in this research incorporate each of the above suggestions. The success of each program results from the dynamic relationships that are formed, the value in real-world big ideas, and a movement of responsibility and reliability amongst young adults. Young adults are the seeds of the future and in order for them to be healthy budding individuals, they need access to the necessary amendments and rich nutrients required for both surviving and thriving; moreover, they need the opportunity to share the bounties of their harvest with others in the community and to do so in meaningful ways. 


\section{REFERENCES}

Algozzine, B., \& Hancock, D. R. (2006). Doing case study research. New York, NY: Teacher's College Press.

Alinsky, S. (1971). Rule for radicals: A pragmatic primer for realistic radicals. New York, NY: Random House Inc.

Berry, W. (1972). A continuous harmony: Essays cultural and agricultural. Washington, DC: Shoemaker \& Hoard.

Berry, W. (1987). Home economics. New York, NY: North Point Press.

Berry, W. (2009). Bringing it to the table: On farming and food. Berkeley, CA: Counterpoint.

Bixler, R. D., \& James, J. J. (2008). Children's role in meaning making through their participation in an environmental education program. Journal of Environmental Education, 39(4), 44-59.

Bonzo, M. J., \& Stevens, M. R. (2008). Wendell Berry and the cultivation of life: A readers’ guide. Grand Rapids, MI: Brazos Press.

Brown, L. (2009). Plan B 4.0: Mobilizing to save civilization. New York, NY: W.W. Norton \& Company.

Campbell, M. C. (2004). Building a common table: The role for planning in community food systems. Journal of Planning Education and Research, 23, 341-355.

Chambers, S. (2007). Minority empowerment and environment justice. Urban Affairs Review, 43(1), 28-54.

Chiseri-Strater, E., \& Sunstein, B. (2006). Fieldworking: Reading and writing research ( $3^{\text {rd }}$ ed.). Englewood Cliffs, NJ: Prentice Hall.

Coles, G. (2009). Hunger, academic success, and the hard bigotry of indifference. Rethinking Schools, 23(2), 34-37. 
Conroy, C., \& Sipple, J. (2001). A case study in reform: Integration of teacher education in agriculture with teacher education in mathematics and science. Journal of Vocational Education Research, 26(2), 206-243.

Cutter, S. (1995). Race, class and environmental justice. Progress in Human Geography, 9(1), 111-121.

Davis, P. (2007). Storytelling as a democratic approach to data collection: Interviewing children about reading. Educational Research, 49(2), 169-184.

Delpit, L. (2006). Other people's children: Cultural conflict in the classroom. New York, NY: New Press.

Deutsch, N., \& Jones, J. (2008). "Show me an ounce of respect”: Respect and authority in adult-youth relationships in after-school programs. Journal of Adolescent Research, 23(6), 667-688.

Duster, T., \& Waters, A. (2006). Engaged learning across the curriculum: The vertical integration. Liberal Education, 1, 42-47.

Fahmy, E. (2006). Social capital and civic action: A study of youth in the United Kingdom. Young: Nordic Journal of Youth Research, 14(2), 101-118.

Fien, J. (2000). Young people and the environment: Implications of a study of youth environmental attitudes and education in the Asia pacific region for curriculum reform during the UN decade of education for sustainable development. Environment, Education and Society, 12, 1-21.

Freire, P. (1970). Pedagogy of the oppressed. New York, NY: Herder and Herder.

Fuller, B., \& Rapoport, T. (1984). Indigenous evaluation: Distinguishing the formal and informal organizational structures of youth programs. Evaluation Review, 8(1), 25-44.

Garden Raised Bounty Website. (2010). Employment program. Retrieved from http://www.goodgrub.org/youth/employment

Gough, N. (1990). Healing the earth within us: Environmental education as cultural criticism. Journal of Experiential Education, 13(3), 12-17.

Guba, E. G., \& Lincoln, Y. S. (1994). Competing paradigms in qualitative research. In N. K. Denzin \& Y. S Lincoln (Eds.), Handbook of qualitative research (pp. 105117). London: Sage. 
Guthman, J. (2008). Bringing good food to others: Investigating the subjects of alternative food practice. Cultural Geographies, 15, 431-447.

Guthman, J., Raskin, S., \& Short, A. (2007). Food deserts, oases, or mirages: Small market and community food security in the San Francisco Bay area. Journal of Planning Education and Research, 26, 352-364.

Hale, A., Snow-Gerono, J., \& Morales, F. (2008). Transformative education for culturally diverse learners through narrative and ethnography. Teaching and Teacher Education, 24, 1413-1425.

Hess, D., \& Winner, L. (2007). Enhancing justice and sustainability at the local level: Affordable policies for urban governments. Local Environment, 12(4), 379-395.

hooks, b. (2003). Teaching community: A pedagogy of hope. New York, NY: Routledge.

Jones, V. (2008). The green collar economy: How one solution can fix two of our biggest problems. New York, NY: Harper Collins.

Kahn, P. H., Jr., \& Friedman, B. (1998). On nature and environmental education: Black parents speak from the inner city. Environmental Education Research, 4(1), 25-39.

Kanter, A. (2001). After-school programs for adolescents. NASSP Bulletin, 85(12), $12-21$.

Kaplan, R. (1973). Some psychological benefits of gardening. Environment and Behavior, 5, 145-161.

Khare, R. S. (1998). The issue of "right to food" among Hindus: Notes and comments. Contributions to Indian Sociology, 32, 253-278.

Kingsolver, B. (with Hoppe, S., L., \& Kingsolver, C.). (2007). Animal, vegetable, miracle: A year of food life. New York, NY: Harper Collins Publishers.

Klindienst, P. (2006). The earth knows my name: Food culture, and sustainability in the garden of ethnic Americans. Boston, MA: Beacon Press.

Kozol, J. (1991). Savage inequalities: Children in America's schools. New York, NY: Crown Publishers.

Kugler, M. (2001). After-school programs are making a difference. NASSP Bulletin, 85(3), 3-10. 
Lang, T., \& Milstones, E. (2008). The atlas of food: Who eats what, where, and why. Berkeley and Los Angeles, CA: University of California Press.

Leadership. (2010). In Merriam-Webster online dictionary. Retrieved from http://www.merriam-webster.com/dictionary/leadership

LeCompte, M., \& Schensul, J. (1999). Designing and conducting ethnographic research: Ethnographer's toolkit. Lanham, MD: Atamira Press.

Louv, R. (2005). Last child in the woods: Saving our children from nature-deficit disorder. Chapel Hill, NC: Algonquin Books.

Marouli, C. (2002). Multicultural environmental education: Theory and practice. Canadian Journal of Environmental Education, 7(1), 26-42.

McClanahan, L. G. (2009, Summer). Educating Heather: First-person narratives bring climate change closer to home. Rethinking Schools, 23(4), 44-47.

McKenzie, K. B., Hernandez, F., Fierro, E., Capper, C. A., Dantley, M., Gonzalez, M. L., \& Cambron-McCabe, N., \& Scheurich, J. J. (2007, February). From the field: A proposal for educational leaders for social justice. Educational Administration Quarterly, 44(1), 111-130.

McKeown, R. (2002). Education for sustainable development toolkit, version 2. Knoxville, TN: University of Tennessee, Waste Management Research and Education Institute. Retrieved from http://www.esdtoolkit.org

Metropolitan Portland's Geography of Opportunity. (n.d.). Regional Equity Atlas Project. Maps. Retrieved from http://www.equityatlas.org/

Neblett, T. F. (1937). Youth movements in the United States. The ANNALS of the American Academy of Political and Social Science, 194, 141-151.

Nelson, M. K. (Ed.). (2008). Original instructions: Indigenous teachings for a sustainable future. Rochester, VT: Bear \& Company.

Noddings, N. (1992). The challenge to care in schools: An alternative approach to education. New York, NY: Teachers College Press.

Orr, D.W. (1992). Ecological literacy: Education and transition to a postmodern world. Albany, New York, NY: SUNY Press.

Orr, D. W. (2002). The nature of design: Ecology, culture, and human intention. New York, NY: Oxford University Press. 
Ozer, E. J. (2007). The effects of school gardens on students and schools:

Conceptualization and considerations for maximizing healthy development. Health Education and Behavior, 34, 846-861.

Parajuli, P. (2006, Spring). Learning suitable to life and livability: Innovations through learning gardens. Connections: Journal of the Coalition for Livable Future. Retrieved from http://clfuture.org/publications/ connections/ SchoolsConnections.pdf

Pelo, A. (2009, Summer). A pedagogy for ecology. Rethinking Schools, 23(4), 30-35.

Pitts, J. (2002). Changing youth justice. Youth justice, 3(1), 5-20.

Polak, P. (2009). Out of poverty: What works when traditional approaches fail. San Francisco, CA: Berrett-Koehler Publishers.

Pollan, M. (2006). The omnivore's dilemma: A natural history of four meals. New York, NY: Penguin Books.

Pothukuchi, K. (2004). Community food assessment: A first step in planning for community food security. Journal of Planning Education and Research, 23, 356-377.

Pusch, M. D. (1981). Multicultural education: A cross-cultural training approach. Chicago, IL: Intercultural Press. Inc.

Raja, S., \& Ma, C. (2008). Beyond food deserts: Measuring and mapping racial disparities in neighborhood food environments. Journal of Planning Education and Research, 27, 469-482.

Rapley, T. J. (2001). The art (fullness) of open-ended interviewing: Some considerations on analyzing interviews. Qualitative Research, 1, 303-323.

Robbins, J. (1987). Diet for a new America: How your food choices affect your health, happiness, and the future of life on earth. Walpole, NH: Stillpoint.

Rooney, J. (1995). Organizing the South Bronx. Albany, NY: State University of New York Press.

Saunders, A. (2006). Book review: Who has the youth, has the future: Three youth movements in twentieth-century Germany. Journal of Contemporary History, 4(1), 175-183.

Savin-Baden, M., \& Van Niekerk, L. (2007). Narrative inquiry: Theory and practice. Journal of Geography in Higher Education, 31(3), 495-472. 
Schneider, J. A. (2007). Connections and disconnections between civic engagement and social capital in community-based nonprofits. Nonprofit and Voluntary Sector Quarterly, 36, 572-597.

Serow, R. (1989). Community service, religious commitment, and campus climate. Youth and Society, 21(1), 105-119.

Sharma, A. (2007). The changing agricultural demography of India: Evidence from a rural youth perception survey. International Journal of Rural Management, 3, 27-41.

Shiva, V. (2005). Earth democracy: Justice, sustainability and peace. Cambridge, MA: South End Press.

Shiva, V. (2007). Manifestos on the future of food and seed. Cambridge, MA: South End Press.

Singer, P., \& Mason, J. (2006). The ethics of what we eat: Why our food choices matter. Emmaus, PA: Rodale Press.

Smock, K. (2004). Democracy in action: Community organizing and urban change. New York, NY: Columbia University Press.

Sterling, S. (2001). Sustainable education: Re-envisioning learning and change. United Kingdom: Green Books ltd.

Thorp, L. (2006). Pull of the earth: Participatory ethnography in the school garden. Lanham, MD: Altamira Press.

Thorp, L., \& Townsend, C. (2001, December 21). Agricultural education in an elementary school: An ethnographic study of a school garden. Paper presented at the $28^{\text {th }}$ Annual National Agricultural Education Research Conference, New Orleans, LA.

Tso, J., \& Hill, C. (2006). Understanding cultural competency in experiential environmental education programs: A report from the cultural competency assessment project. Boston, MA: Barr Foundation.

Vallianatos, M., Gottlieb, R., \& Haase, M. A. (2004). Farm-to-school: Strategies for urban health, combating sprawl, and establishing a community food systems approach. Journal of Planning Education and Research, 23(4), 414-423.

Waters, A., \& Duster, T. (2006). Engaging learning across the curriculum: The vertical integration. Liberal Education, 1, 42-47. 
Wekerle, G. R. (2004). Food justice movements: Policy, planning, and networks. Journal of Planning Education and Research, 23, 378-386.

Williams, D. R. (2008). Listening to nature: Cultivating ecological literacy through learning gardens. Oregon English Journal, 30(1), 12-15.

Wilson, W. J. (1996). When work disappears: The world of the new urban poor. New York, NY: Random House Inc.

Winne, M. (2008). Closing the food gap: Resetting the table in the land of plenty. Boston, MA: Beacon Press.

Wynne, W. D. (2006). Civic engagement through civic agriculture: Using food to link classroom and community. Teaching Sociology, 34, 224-235.

Xu, S., Connelly, F. M., He, M. F., \& Phillion, J. (2007, August). Immigrant students' experience of schooling: A narrative inquiry theoretical framework. Journal of Curriculum Studies, 39(4), 399-422.

Youniss, J., Mclellan, J. A., Su, Y., \& Yates, M. (1999, April). The role of community service in identity development: Normative, unconventional, and deviant orientations. Journal of Adolescent Research, 14(2), 248-261.

Youniss, J., \& Yates, M. (1997). Community service and social responsibility in youth. Chicago, IL: The University of Chicago Press.

Zehr, H. (2002). The little book of restorative justice. Intercourse, PA: Good Books.

Zenkov, K., \& Harmon J. (2009, April). Picturing a writing process: Photovoice and teaching writing to urban youth. Journal of Adolescent and Adult Literacy, 52(7), 557-584. 
APPENDIX A

INTERVIEW QUESTIONS 
1. How long have you lived in the Seattle/Ashland area?

2. How long have you been involved in the Garden-Raised Bounty/ Job Council with Medford Opportunity High School ?

3. What is your role in the program?

4. What inspired you to become a member of the Garden-Raised Bounty/ Job Council with Medford Opportunity High School?

5. Are there specific tasks or organizational modalities that keep you involved (sustainable)?

6. Why is it important that young adults assist their community and learn vocational training (life skills) that is encompassed in a program like Garden-Raised Bounty/ Job Council with Medford Opportunity High School?

7. Why is it important that young adults (assist and empower their community) are involved? By meeting their basic needs of food security? (With food?)

8. (Is it?) How is farming/gardening a good model and way to revitalize a lowincome, often forgotten neighborhood/community?

9. Do you see yourself learning life-skills and training that you can use when you have completed the Garden-Raised Bounty Job Council with Medford Opportunity High School? (Are there skills that you take with you that you didn't expect when first working in the program>?)

10. Do you view yourself as a leader in your community? If so, what has made you feel this way? Is there a story you would like to share that involves this relationship?

11. Do other young adults in your school community know about the program? If so, do they inquire about it?

12. Why are young adults vital in community-based projects?

13. Would you like other communities locally, nationally, and globally to use this model as a way to empower young people and feed their communities?

14. What would your community look like without Garden-Raised Bounty/ Job Council with Medford Opportunity High School?

15. What would the young adults role be in your community without Garden-Raised Bounty / Job Council with Medford Opportunity High School?

16. Has your personal leadership evolved outside of the Garden-Raised Bounty / Job Council with Medford Opportunity High School?

17. Has your participation in Garden-Raised Bounty / Job Council with Medford Opportunity High School program influenced your relationship with food 
policies? Do you care more about food and policy change now than before you were in the program?

18. Has your participation in Garden-Raised Bounty / Job Council with Medford Opportunity High School program influenced your relationship with the natural environment?

19. Has your participation in Garden-Raised Bounty / Job Council with Medford Opportunity High School influenced your personal power as an individual?

20. How are the community members involved in the program, and do they have a voice in decisions?

21. Do you remember when there was no Garden-Raised Bounty / Job Council with Medford Opportunity High School program in this city? If so, what was it like? Are there major changes that you can recall?

22. Would you like to see a program like the one you are in, as an international or national model?

23. Lastly, is there anything else you would like to share? 
APPENDIX B

FIELD NOTES OUTLINE AND OBSERVATION CONSIDERATIONS 
1. An outsider's perspective.

2. What is the general mood?

3. Who leads most among the youth participants, and what traits are apparent?

4. Tasks throughout day?

5. Vocational training/ skills shares and utilized?

6. How does the community respond to their service?

7. Relationships amongst the staff and participants?

8. Traits of community engagement? 